\title{
Analysis and forecast of marine economy development in China
}

\author{
Yin Kedong \\ Shandong University of Finance and Economics, Jinan, China and \\ Ocean University of China, Qingdao, China \\ Zhe Liu and Caixia Zhang \\ Ocean University of China, Qingdao, China \\ Shan Huang \\ School of Economics, Ocean University of China, Qingdao, China, and \\ Junchao Li, Lingyun Lv, Xiaqing Su and Runchuan Zhang \\ Ocean University of China, Qingdao, China
}

\begin{abstract}
Purpose - In recent years, China's marine industry has maintained rapid growth in general, and marinerelated economic activities have continued to improve. The purpose of this research is to analyze the basic situation of China's marine economy development, identify the problems therein, forecast development trends and propose policy recommendations accordingly.

Design/methodology/approach - This research conducts a comprehensive and detailed analysis of the development of China's marine economy with rich data in diversified aspects. The current situation of China's marine economy development is analyzed from the perspective of scale and structure, and the external and internal development environment of China's marine economy is discussed. With the application of measurement and prediction method such as trend extrapolation, exponential smoothing, grey forecasting and neural network method, the future situation of China's marine economy development is forecasted.

Findings - In a complex environment where uncertainties at home and abroad have increased significantly, China's marine economy development suffers tremendous downward pressure in recent years. As China has achieved major achievements in the prevention and control of the COVID-19 epidemic, the marine economy development will gradually return to normal. It is estimated that the gross marine production value in 2022 will exceed 10 trillion yuan. China's marine economy will continue to maintain a steady growth trend in the future, and its development prospects will remain promising.

Originality/value - This research explores the current situation and trends of China's marine economy development and puts forward policy recommendations to promote the steady and health development of China's marine economy accordingly.
\end{abstract}

Keywords Marine economy, Development environment, Analysis and forecast

Paper type Translated paper

1. Analysis of the basic situation of China's marine economy from 2019 to 2020 At present, China's economy has entered a critical period of transforming development mode, optimizing economic structure and transforming growth momentum. The internal and external environment is complex and harsh. From 2019 to 2020, under a background

(C) Yin Kedong, Zhe Liu, Caixia Zhang, Shan Huang, Junchao Li, Lingyun Lv, Xiaqing Su and Runchuan Zhang. Published in Marine Economics and Management. Published by Emerald Publishing Limited. This article is published under the Creative Commons Attribution (CC BY 4.0) licence. Anyone may reproduce, distribute, translate and create derivative works of this article (for both commercial and noncommercial purposes), subject to full attribution to the original publication and authors. The full terms of this licence may be seen at http://creativecommons.org/licences/by/4.0/legalcode

This research is supported by the National Social Science Fund Major Projects (14ZDB151); National Science Foundation of China under Grants (41701593, 71371098, 71571157); National Key Research and Development Program of China (2016YFC1402000); The Ministry of Education Philosophy and Social Sciences Development Report Cultivation Project (13JBGP005).

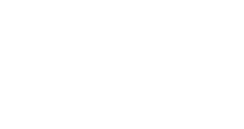


MAEM

5,1

2

of overall macroeconomic pressure, China's marine economy adhered to the optimization and upgrading of industrial structure, constantly strengthened its technological research and development capacity, increased industrial synergy level, promoted land-sea coordination and constantly accelerated integration of marine economy in the macroeconomy. It has broad prospects for development, but also faces challenges that cannot be ignored.

As an international leading maritime power, China's marine economy has formed a comprehensive development model by taking scientific management of the sea as the basic principle, sea-land coordination as the development path and ecological protection of the sea as the development criterion. In today's world, coastal countries have gradually shifted their development focus from the land economy to the marine economy. The level of development of the marine industry has become an important indicator to measure a country's comprehensive national strength. From the perspective of industrial development, the value added by the marine industry in China and some coastal areas has been increasing. From the perspective of industrial structure, the industrial structure of China's marine economy has been continuously optimized, the marine "three, two and one" industrial pattern has become prominent, and the proportion of the tertiary industry has increased. From the perspective of regional development, marine industry in coastal areas shows uneven development, and there are differences in marine leading industries: however, there are certain similarities in various development issues, which are mainly reflected in the weak connection between China's land industry and marine industry, showing a certain gap in production technology compared with other international marine powers, and the management system of marine resource development needs to be improved. In addition, there is still a contradiction between the overall and the local development of marine resources in China and the phenomenon of marine industry isomorphism in regional development persists. These problems warrant further investigation and require solutions in the future.

\subsection{Analysis on the scale of China's marine economy}

China Marine Economic Statistics Bulletin 2019 explains the relative concepts as follows: Gross Ocean Product includes added value from the marine industry and added value from marine-related industries. The marine industry refers to the production and service activities involved in the development, utilization and protection of the ocean. It is composed of the major marine industries and marine scientific research education management services. Among them, ocean-related industries denote upstream and downstream industries that take various inputs and outputs as links and form technical and economic links with major marine industries.

1.1.1 Analysis of the development of Gross Ocean Product of China. In 2019, the Gross Ocean Product of China increased by $6.2 \%$, reaching 8,941.5 billion yuan. Before 2010, the rate of growth in Gross Ocean Product fluctuated; due to the influence of SARS epidemic, there was a period of slow development with a growth rate of less than $5 \%$ in 2003, although this rebounded in 2004. There followed a decline owing to the influence of the global financial crisis in 2008. With the strengthening of marine development and utilization in China, the Gross Ocean Product underwent steady growth from 2011 to 2019, however, affected by the expansion of the Gross Ocean Product base, the slowdown in the development of major marine industries and ocean-related industries caused by the structural adjustment of the marine industry, and macroeconomic fluctuations both at home and abroad, the growth rate of the Gross Ocean Product has fluctuated and declined compared with previous years, with an average annual growth rate of about $7.48 \%$. Before 2006, the proportion of Gross Ocean Product in the total GDP of China tended to rise, then fluctuated slightly, but tended to be stable at $9-10 \%$. In the future, China's marine economic development will be challenged by many uncertain factors, such as Sino-US trade friction, the "Indo-Pacific Strategy" proposed 
by the United States and the spread of the COVID-19 epidemic, which will have a negative impact on the economic environment. Meanwhile, China also actively seeks international cooperation, including promulgation of the Belt and Road Initiative in 2013, promoting the formal establishment of the AIIB in 2015. In addition, in order to promote the stable and sound development of marine economy, China actively implements the strategy of revitalizing the sea through science and technology, accelerates the construction of marine power and establishes free trade zones in coastal areas (Figure 1).

1.1.2 Analysis of value-added development of marine industry of China. 1.1.2.1 The added value of major marine industries. From 2001 to 2019, the added value of China's major marine industries showed a long-term stable growth trend. The added value of major marine industries was about 385.66 billion yuan in 2001 and reached 3,572.4 billion yuan in 2019 . Affected by the SARS epidemic, the development of major marine industries such as coastal tourism and transportation industry was suspended, which decreased the proportion of their added value in the added value of marine industries to $66.6 \%$ in 2003 , where after it gradually increased. Later, due to the influences of the global financial crisis in 2008, the proportion dropped to $68 \%$ in 2009 . Subsequently, governments at all levels took steps to address the economic downturn, and this proportion increased to $70.7 \%$ in 2010 and reached the highest point of at $71.1 \%$ in 2011 . Since then, the proportion of added value of major marine industries has been declining year-on-year with the adjustment of the marine industrial structure. Among them, marine fisheries have been upgraded and their structure optimized and adjusted. The marine fishing output declined sharply owing to the decreasing fishery resources and increasing ecological protection requirements. Although marine aquaculture output increased in relative terms, the mode of aquaculture adopted tended to be more environmentally friendly. Overall, the proportion of marine fishery added value showed a downward trend. In recent years, due to the slowdown in international demand growth and the decline in global shipping prices, the marine transportation industry has maintained its growth, albeit at a slower pace, and the proportion of its added value to the added value of the

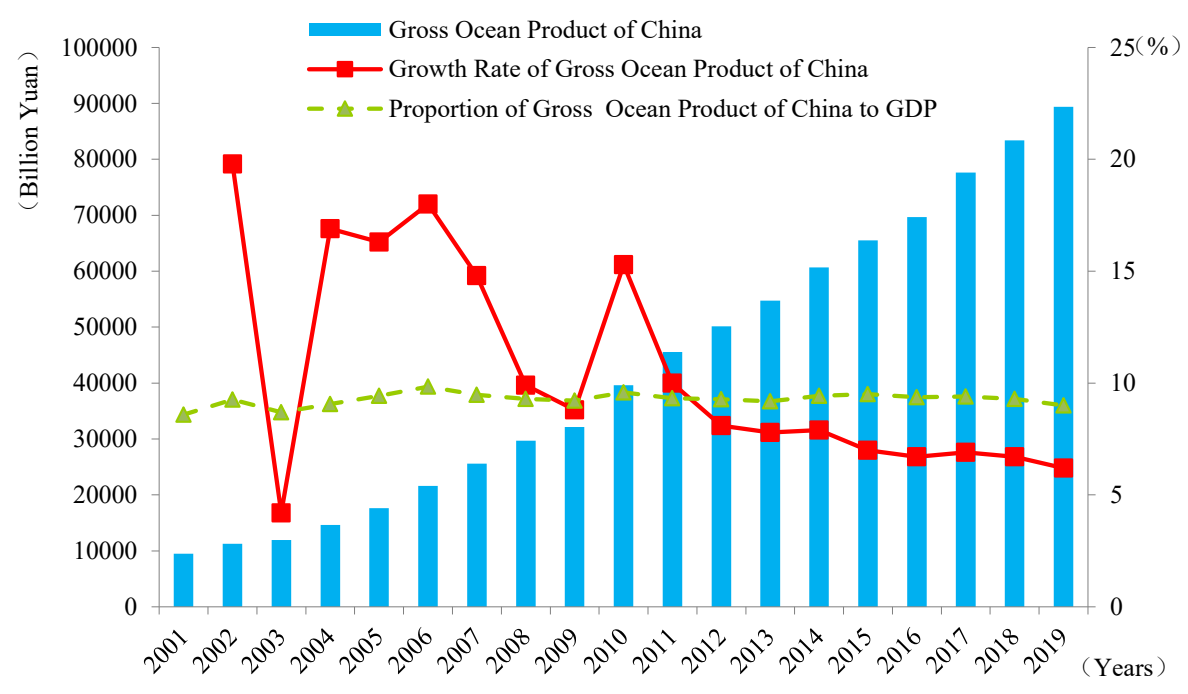

Source(s): China Ocean Statistics Yearbook (2002-2017); China Marine Economic Statistics Bulletin (2017-2019)
China's marine economy development

Figure 1.

Development of China's Gross Ocean

Product from 2001 to 2019 
MAEM

5,1

4

marine industry has also been decreasing. Because of influences arising from oil spills and other unexpected events, adjustment of global oil and gas production, fluctuation of oil price and other factors, the growth rate of the offshore oil and gas industry slowed down or even exhibited negative growth from 2011 to 2017. Until 2018, the increase in natural gas demand drove the added value of the offshore oil and gas industry to rebound, but the proportion of its added value in the added value of the marine industry still decreased. In addition, the growth rate of industries, such as marine engineering and construction, marine shipbuilding and so on, has dropped somewhat due to influences of macro-economy. Among the major marine industries with a large share of the total value, only coastal tourism maintained steady, rapid development (Figure 2).

1.1.2.2 The added value of the marine scientific research education management service industry. From 2001 to 2019, the marine scientific research education management service industry witnessed steady development, and its added value increased rapidly from 187.7 billion yuan in 2001-2,159.1 billion yuan in 2019 (with a growth rate of $8.3 \%$ in 2019). In recent years, China' implemented the plan of rejuvenating the sea and accelerated the construction of a maritime power by means of science and technology, governments at all levels have paid increasing attention to marine scientific research education management services. Especially since 2011, the proportion of its added value in the added value of marine industry has continued to grow. Among them, the numbers of marine practitioners, marine scientific research institutions, marine science and technology topics and research papers have been constantly increasing as well as the numbers of colleges and universities offering marine majors, marine professional teachers and marine professional graduates. Marine scientific research education has developed steadily. With the attention paid to the degradation of resources and serious pollution caused by unreasonable development over the years, the requirements of governments at all levels for ecological and environmental protection have been also increasing. The state has introduced relevant laws and regulations on marine ecological protection, such as Marine Environmental Protection Law in 2017. Marine environmental protection and marine management-related industries have been gradually valued and achieved further development. China's economic structure is gradually adjusted, and its marine economy has entered a new normal. The improvement of marine scientific

Figure 2.

Value-added development of major marine industries in China from 2001 to 2019

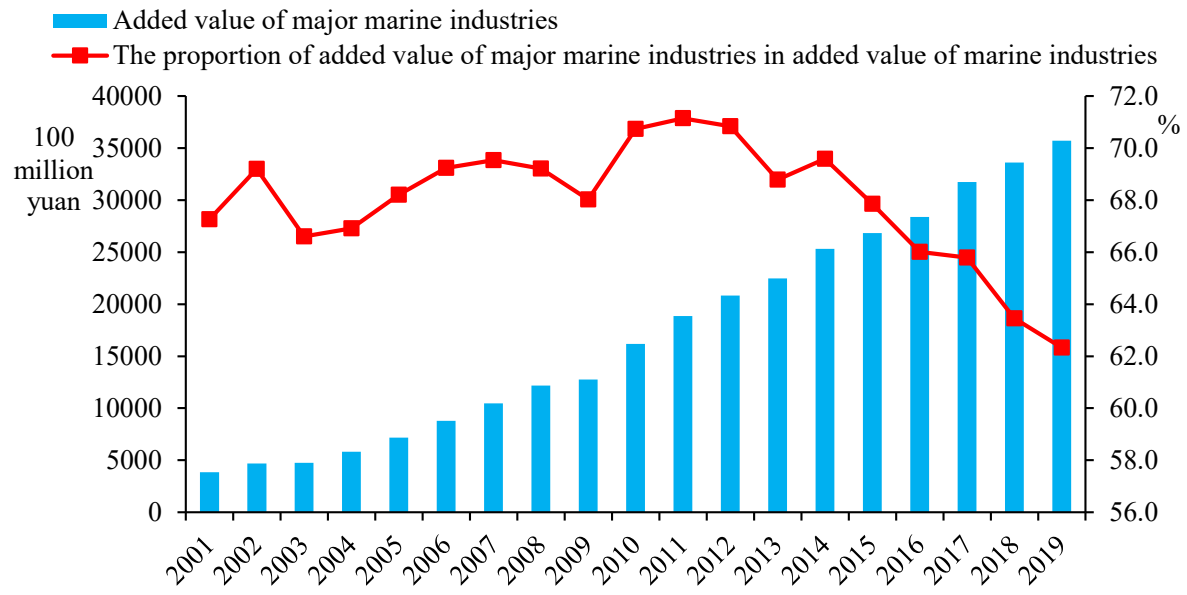

Source(s): China Ocean Statistics Yearbook (2002-2017); China Marine Economic Statistics Bulletin (2017-2019) 
research has also laid a foundation for the development of marine information, marine technology service industry and other industries (Figure 3).

1.1.2.3 The added value of ocean-related industries. From 2001 to 2019, the added value of ocean-related industries in China continued to grow, from 378.48 billion yuan in 2001-3,210 billion yuan in 2019. The growth rate fluctuated significantly, and the average annual growth rate reached about $12.8 \%$. The proportion thereof in China's Gross Ocean Product was relatively stable, at about $40 \%$, showing an increasing trend from 2001 to 2010 and then decreasing after 2011. The reason for this is that ocean-related industries mainly include marine agriculture and forestry, marine instruments and products manufacturing and processing, which are classified as primary and secondary industries. In recent years, the industrial structure of the national economy industry and even the marine field has been adjusted and optimized, which is manifested in the decline of the proportion of primary and secondary industries and the increase of the proportion of tertiary industry. Therefore, the development of marine-related industries has slowed since 2011 (Figure 4).

1.1.3 Analysis of the scale of development of China's regional marine rconomy. In 2019, China's coastal economic zones achieved steady growth of marine economy. Gross Ocean Product of the Bohai Rim Economic Zone was about 2,636 billion yuan, an increase of $8.1 \%$ in nominal terms over the previous year, accounting for $29.5 \%$ of the Gross Ocean Product of China and a decrease of $1.9 \%$ over the previous year. Gross Ocean Product of the Yangtze River Delta Economic Zone was about 2,657 billion yuan, an increase of $8.6 \%$ over the previous year, accounting for about $29.7 \%$ of the Gross Ocean Product of China, an increase of $0.6 \%$ over the previous year. Gross Ocean Product of the Pearl River Delta Economic Zone was about 2,105.9 billion yuan, which accounted for $23.6 \%$ of the Gross Ocean Product of China, indicating an increase of $0.4 \%$ compared with the previous year.

1.1.3.1 Bohai Rim Economic Zone. The Bohai Rim Economic Zone lies in the central region of the North-east Asian Economic Circle. It shows prominent geographical advantages, well developed and convenient transportation, a solid industrial foundation, abundant marine resources, sufficient scientific and technological strength and great development potential. During the tenth Five-Year Plan period, the development of marine economy in coastal areas

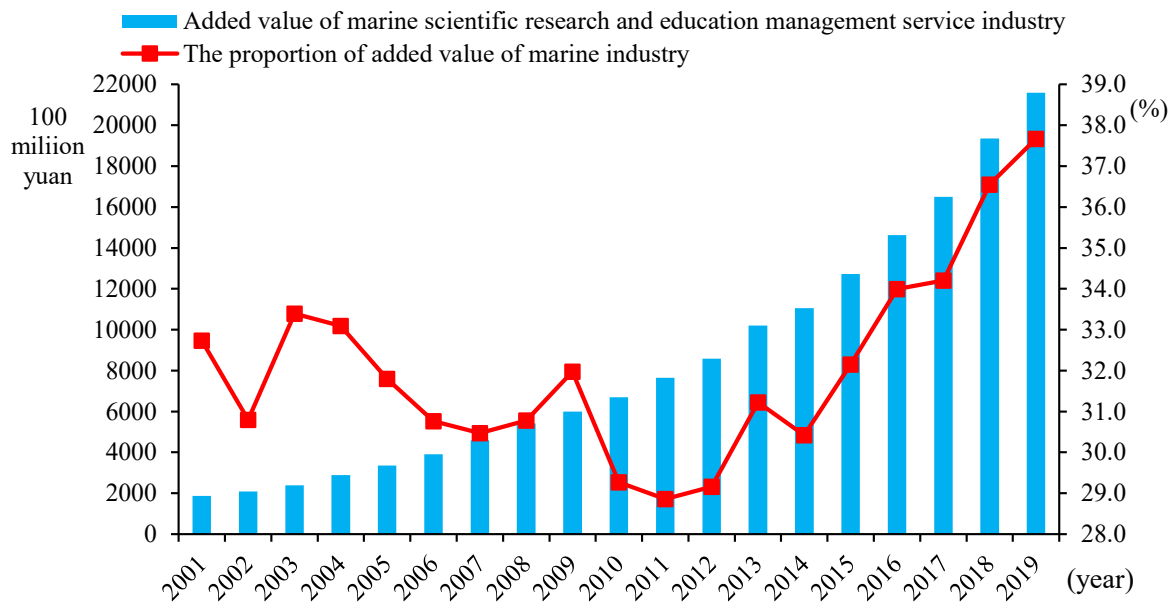

Source(s): China Ocean Statistics Yearbook (2002-2017); China Marine Economic Statistics Bulletin (2017-2019)
China's marine economy development

Figure 3.

Development of marine scientific research education management service industry in China from 2001 to 2019 


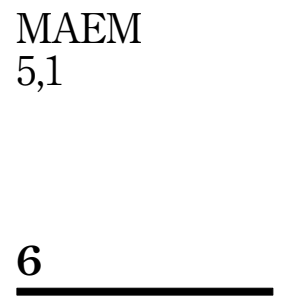

Figure 4.

Development trend of value added of marinerelated industries in China from 2001 to 2019

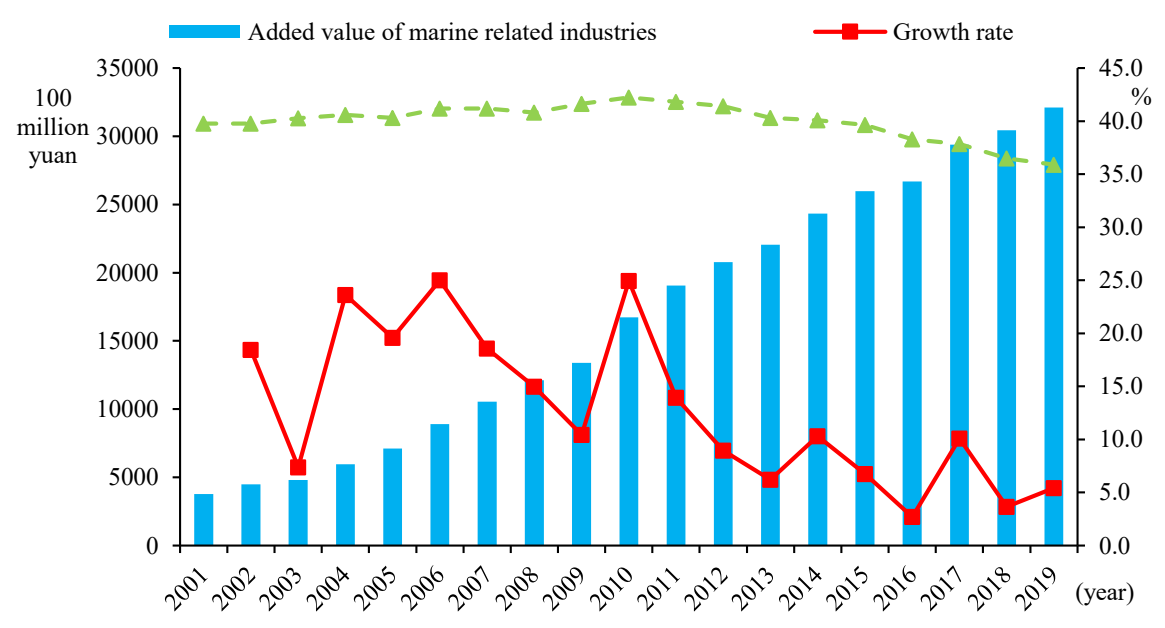

Source(s): China Ocean Statistics Yearbook (2002-2017); China Marine Economic Statistics Bulletin (2017-2019)

achieved remarkable results. The Bohai Rim Economic Zone benefited from the huge advantages of marine industrial clusters and its marine economy grew at a relatively high rate. The proportion of its Gross Ocean Product in the Gross Ocean Product of China and in the regional Gross Ocean Product continued to grow. The global financial crisis in 2008 led to a significant drop in the growth rate of the marine economy, with a slight drop in the two major proportions (about 35 and 16\%). After 2010, the development of marine economy in the Bohai Rim Economic Zone showed a trend of fluctuation and deceleration, and its proportion of the Gross Ocean Product of China presented a slow descending tendency from 2015 to 2019. The reason for this was that in addition to coastal tourism, the development of other pillar industries (marine fisheries, the marine oil and gas industry, etc.) in the Bohai Rim Economic Zone showed a slowdown-trend under the influence of the macroeconomic environment, and the marine economy entered a new phase; however, the proportion of Gross Ocean Product of China to the regional gross domestic product has increased slightly since 2016, reflecting the relatively increased dependence of the Bohai Rim Economic Zone on marine industry (Figure 5).

1.1.3.2 Yangtze River Delta Economic Zone. The Yangtze River Delta Economic Zone mainly includes the land and sea areas under the jurisdiction of Jiangsu Province, Zhejiang Province and Shanghai. It is rich in marine resources and has a sophisticated port shipping system, and relatively strong technological strength and industrial linkage capacity, which makes the Yangtze River Delta Economic Zone the most energetic region of marine economic growth in China. From 2001 to 2019, the marine economy of the Yangtze River Delta Economic Zone continued to develop steadily, with an average annual growth rate of about $18.9 \%$. Thanks to the development of the marine economy during the tenth 5-year plan, the marine economy of the Yangtze River Delta Economic Zone increased rapidly from 2001 to 2006. From 2006 to 2009, the coastal tourism industry, marine transportation industry, marine shipbuilding industry and marine fishery sector with the highest output value contribution were affected by the global financial crisis, which directly led to the decline in marine economic growth. Since then, the added value of coastal tourism increased greatly, and the overall growth rate of marine economy rebounded slightly due to the relevant policy 


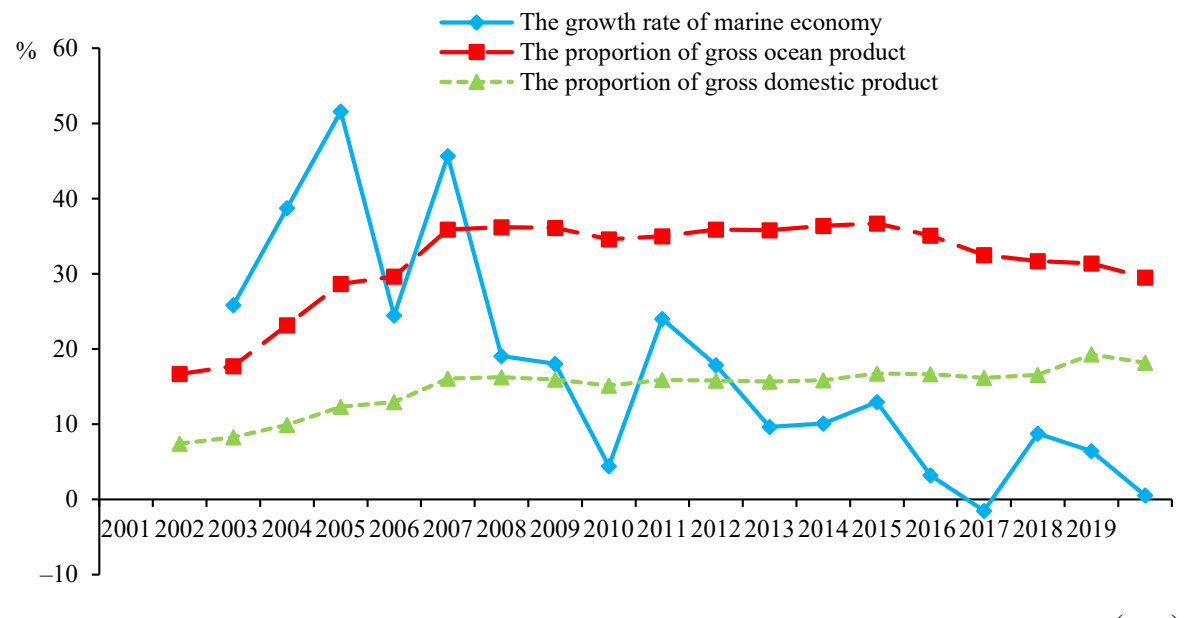

(year) (2017); China Marine Economic Statistics Bulletin (2017-2019); State Statistical Bureau

China's marine economy development

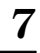

Figure 5.

Marine economic development of Bohai

Rim Economic Zone from 2001 to 2019

support provided by the state and the 2010 Shanghai World Expo. Relatively weak development after 2010 can also reflect China's marine economy entering a new period of shifting growth. During that period, the status of marine scientific research education management service industry agreed with the overall development of the country. After 2011, its growth rate showed an increasing trend, while the rate of growth of marine-related industries decreased, reaching a more sustainable pace of development. The proportion of the Gross Ocean Product in the regional GDP of the Yangtze River Delta Economic Zone has remained stable since 2006, while the proportion of the Gross Ocean Product in the Gross Ocean Product of China decreased slightly, and it was stable at about 30\% (Figure 6).

1.1.3.3 Economic Zone on the West Coast of the Taiwan Straits. The Economic Zone on the West Coast of the Taiwan Straits only includes Fujian Province, and its marine economic scale is relatively limited. Before 2008, the rate of growth of the marine economy in the Economic Zone on the West Coast of the Taiwan Straits fluctuated greatly. In 2008, as the effects of the prevailing international environment decreased, its later development was relatively stable. Over the years, the two proportions of Gross Ocean Product showed a relatively stable, slowly increasing trend, at about 10 and $25 \%$ respectively. It is worth noting that the approval of Development Planning of Fujian Strait Blue Economic Experimental Zone in 2012 has made significant achievements in attracting foreign investment, import and export trade, financial innovation, regional cooperation and other fields in Fujian Province, China. The establishment of Fujian Pilot Free Trade Zone in 2014 has also accelerated the development of marine economy. Since then, the marine economy in the Economic Zone on the West Coast of the Taiwan Straits has continued to develop steadily (Figure 7).

1.1.3.4 Economic Zone of Zhujiang Triangle. The Economic Zone of Zhujiang Triangle mainly consists of Guangzhou, Shenzhen and other coastal areas under the jurisdiction of Guangdong Province, with a high level of economic development. It is the forefront of China's reform and opening up and foreign trade and plays a leading role in the development of the national marine economy. The growth rate of marine economy in the Economic Zone of the Zhujiang Triangle has undergone significant fluctuations due to the influences of 


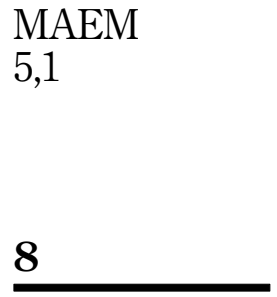

Figure 6.

Development of marine economy in Yangtze River Delta Economic Zone from 2001 to 2019

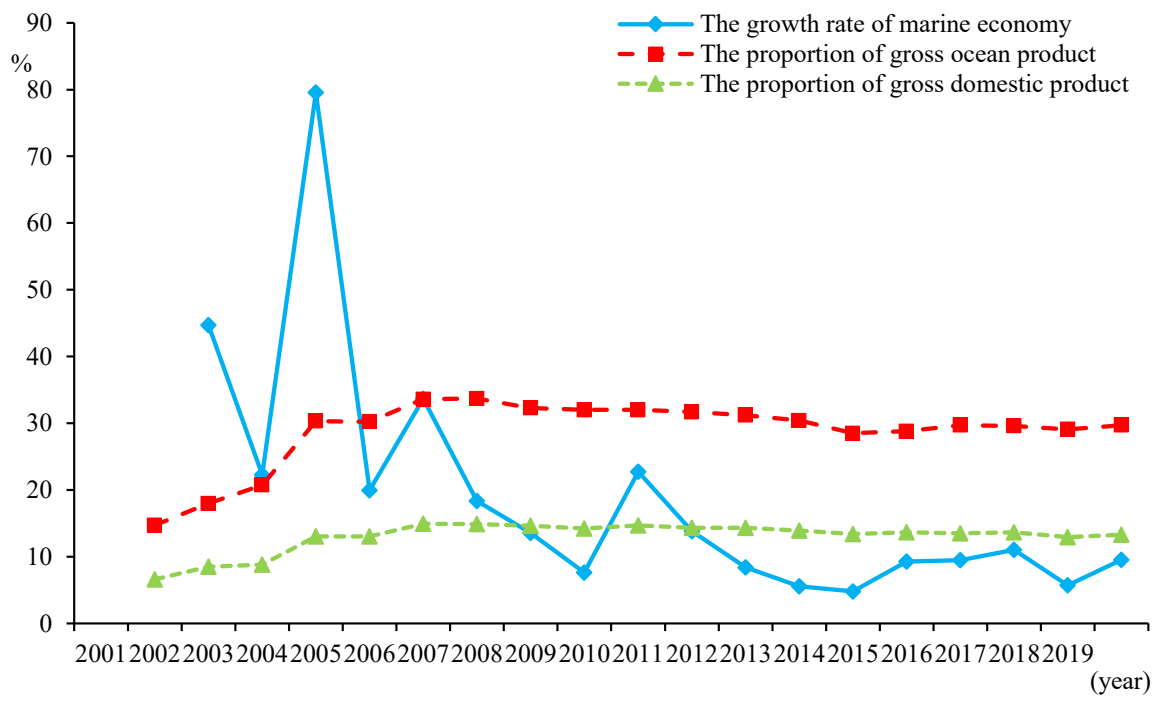

Source(s): China Ocean Statistics Yearbook (2002-2006); China Ocean Statistics Yearbook (2017) China Marine Economic Statistics Bulletin (2017-2019); State Statistical Bureau

the international macroeconomic environment. The proportion of its Gross Ocean Product in the country has increased year-on-year, with an average of $20.5 \%$ and an average of $17.6 \%$ of the total regional product. During the tenth five-year plan period, the marine economy of the Economic Zone of Zhujiang Triangle increased significantly. Marine economy has maintained its rapid development and became a new important growth point of regional economic development during the eleventh five-year period. In 2008, Marine functional zoning of Guangdong Province laid the foundation for more scientific utilization of marine space; Guangdong was listed as a pilot area for national marine economic development in 2011; Guangdong Pilot Free Trade Zone was established in 2014. In recent years, the pillar industries, including coastal tourism, marine transportation and the marine oil and gas industry, have developed steadily. Offshore wind power, marine equipment, marine electronic information and other emerging industries have been supported. Marine innovation ability has been enhanced, green development has been entrenched, and the marine industry has accrued considerable benefits, which has promoted the sustainable and healthy development of marine economy in the Economic Zone of Zhujiang Triangle (Figure 8).

1.1.3.5 Beibu Gulf Economic Zone. The Beibu Gulf Economic Zone with excellent location conditions is located in the southwest of China's coast and has both maritime channels and land connections with ASEAN countries; however, since the Beibu Gulf Economic Zone only includes parts of Guangxi, the limitation of its regional scope and historical conditions makes the development of the local marine economy relatively slow. The development of marine economy in Beibu Gulf Economic Zone fluctuated significantly from 2001 to 2007, and the average annual growth rate of marine economy after 2007 was about $14.2 \%$. With the increasing attention of the state and the launch of China-ASEAN Free Trade Area in 2010, the Beibu Gulf strengthened international cooperation and promoted openness, and the overall scale of its marine economy demonstrated a steady upward trend. In 2019, Guangxi Free Trade Zone was formally established, and the growth rate of marine economy in Beibu 


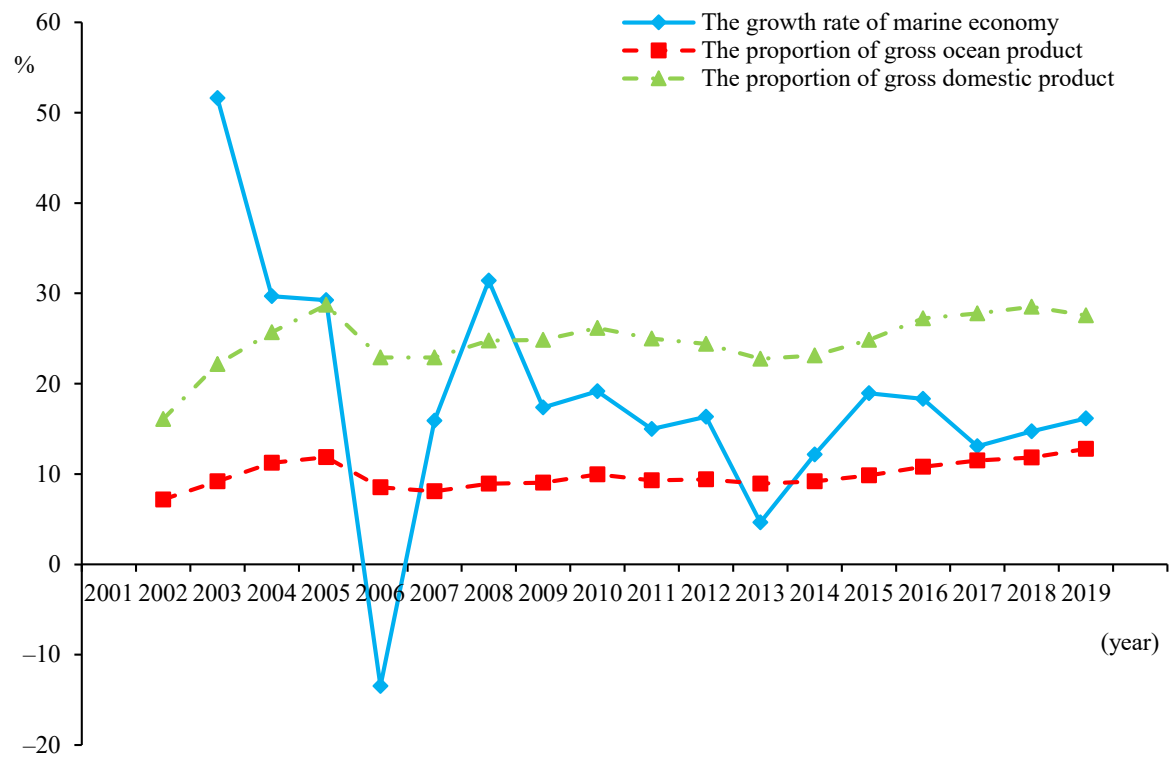

Source(s): China Ocean Statistics Yearbook (2002-2006); China Ocean Statistics Yearbook (2017); China Marine Economic Statistics Bulletin (2017-2019); Fujian Marine and Fisheries Bureau Interpretation of Marine Economy in 2017; Fujian Marine and Fisheries Bureau Provincial Conference on Oceans and Fisheries Held in Rong; State Statistical Bureau

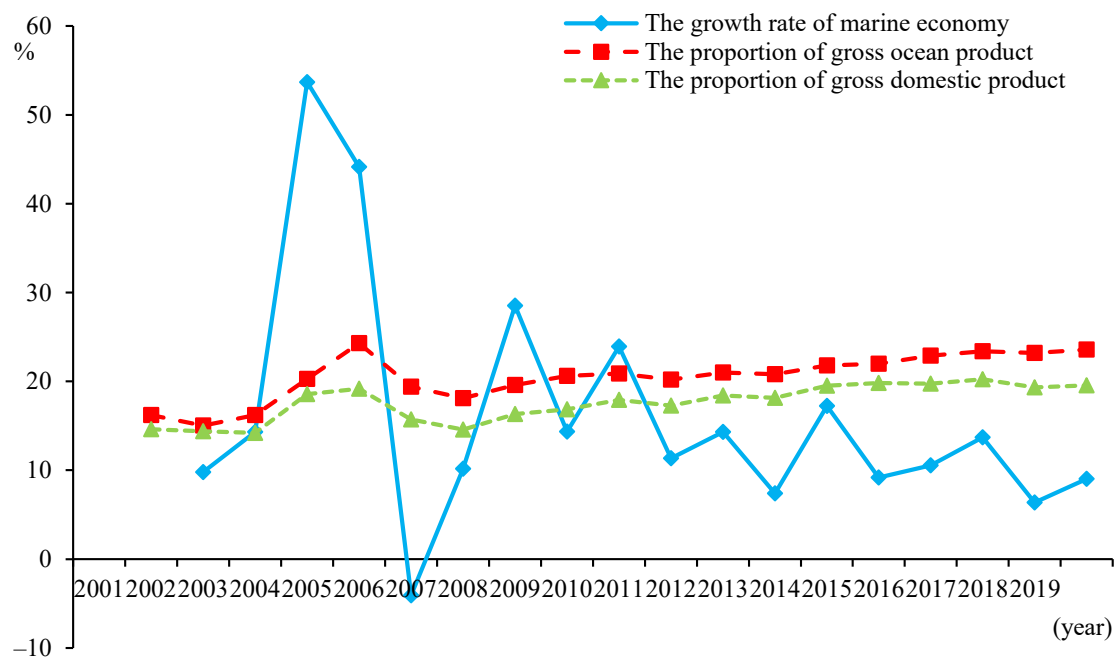

Source(s): China Ocean Statistics Yearbook (2002-2006); China Ocean Statistics Yearbook (2017); China Marine Economic Statistics Bulletin (2017-2019); Guangdong Marine Economic Development Report (2020); State Statistical Bureau
China's marine economy development

Figure 7.

The development of marine economy in the West Coast Economic Zone of the Straits from 2001 to 2019

Figure 8. Development of marine economy in economic zone of Zhujiang

Triangle from 2001 to 2019 
MAEM

5,1

Gulf Economic Zone increased. The development of marine economy in Beibu Gulf Economic Zone still has broad prospects (Figure 9).

\section{Analysis of marine industry structure in China}

\subsection{Changes to three marine industrial structures}

From the overall development of marine industry, China's gross marine product showed an overall upward trend from 2001 to 2019. The proportion of the three major marine industries has changed from 6.8:43.6:49.6 in 2001 to 4.2:35.8:60 in 2019 from the perspective of the relative scale of marine industry. The proportion of the primary and secondary industries in the Gross Ocean Product has decreased significantly in the past 2 decades, while the proportion of the marine tertiary industry in China's marine industry increased significantly. In recent years, affected by the environment at home and abroad, the rates of growth of the three major marine industries have declined significantly. Among them, the rate of growth for tertiary industries is significantly greater than that of the primary and secondary industries (Figure 10). At present, China's marine economic system continues to consolidate the development pattern of " $3-2-1$ ", and the marine industry is expected to continue to develop.

Since the start of the 21st century, the value added of China's total marine industry (including the three major industries) has grown steadily from 2001 to 2019; however, because of influences of various domestic and foreign emergencies, the value added of China's various marine industries has grown slowly in some years or relative to the previous year. Affected by SARS in 2003, China's marine economic development momentum was insufficient, and the marine tertiary industry was the most affected, its added value growth rate was only $2.54 \%$ (Figure 10). Due to the influences of the financial crisis in 2009, China's marine economic

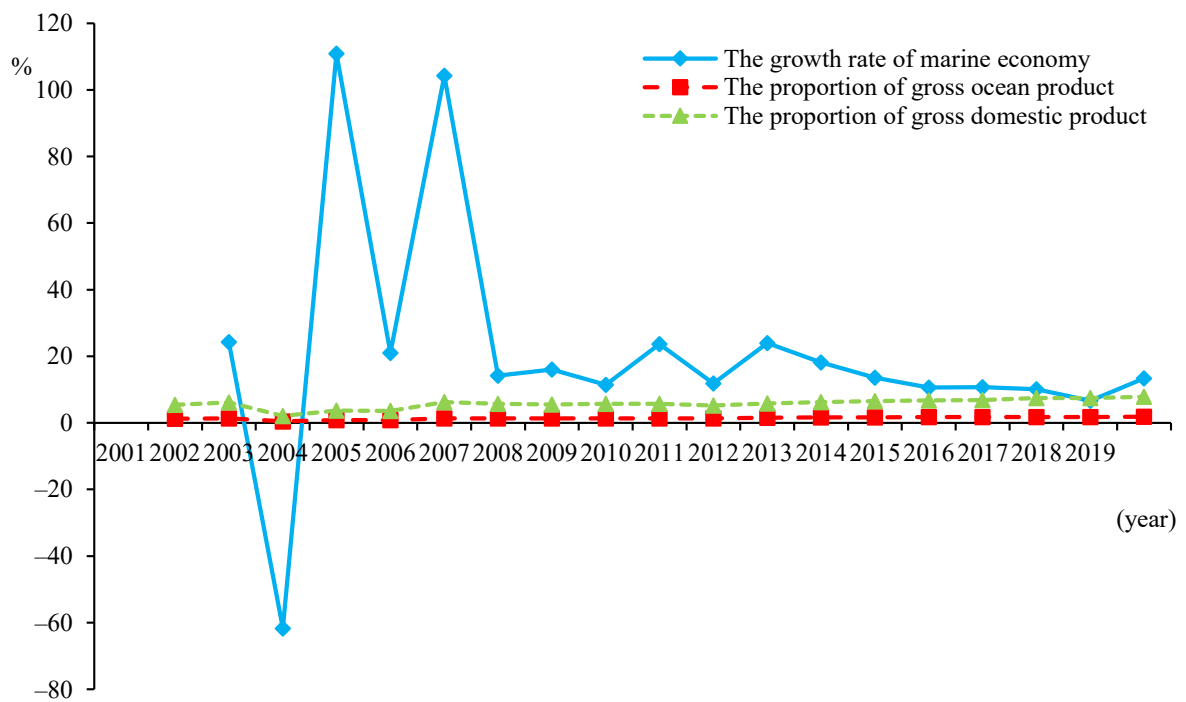

Figure 9.

Development of marine economy in Beibu Gulf economic zone from 2001 to 2019
Source(s): China Ocean Statistics Yearbook (2002-2006); China Ocean Statistics Yearbook (2017); China Marine Economic Statistics Bulletin (2017-2019); Guangxi Marine Economic Statistics Bulletin in 2019; State Statistical Bureau 
development slowed. The coastal tourism industry suffered a huge impact, and the entire marine tertiary industry rate of growth was only $7.62 \%$ (Figure 10). Facing the decline of oil and gas production and the grim situation at home and abroad in 2016, the added value of China's marine secondary industry has declined for the first time since the start of the 21st century (Figure 11). From 2017 to 2019, with the decrease in marine fishing production and the adjustment of fishery production structure, China's marine primary industry has achieved a smooth transition (Figure 11).

The novel coronavirus pandemic started in 2019 would inevitably lead to the decrease in the added value of China's marine industry, and associated marine tertiary industries, which are extremely sensitive to emergencies, were the most affected. During the outbreak of the novel coronavirus pneumonia, many coastal tourist attractions in China were closed and the number of tourists decreased sharply, which caused great losses to the coastal tourism sector in China. After the epidemic situation began to ease, government gradually deregulated. Although China's tourism industry has recovered during this period, the recouping of the losses caused by the coronavirus pandemic requires more time. In the face of the pandemic, some countries or regions have adopted restrictive regional management policies, and the control of sea routes and ports is more stringent, which will inevitably affect the progress of interregional trade, and the marine transportation industry has also been affected to some extent. In addition, marine shipbuilding industry, marine oil and gas industry, marine mining, marine fisheries and other industries have been affected to various extents. According to the effects of local epidemic control and the government's support for rework and reproduction, China's marine industry departments are expected to recover around 2021, and the added value of each industry will increase steadily (based on 2020 values). In 2022, various domestic marine industries will almost return to normal, and the added value will be expected to exceed levels enjoyed before the outbreak.

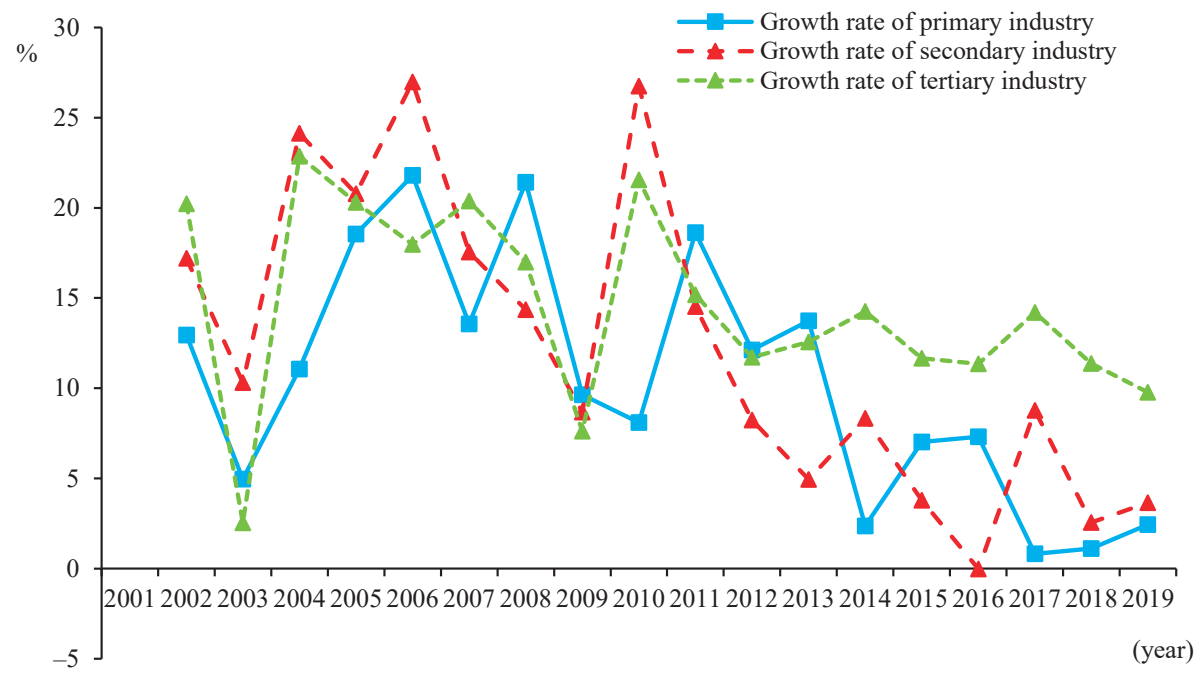

Source(s): China Ocean Statistics Yearbook (2002-2017); China Marine Economic Statistics Bulletin (2017-2019)
China's marine economy development
Figure 10.

Growth trend of the marine industry in

China from 2001 
MAEM

5,1

\section{2}

Figure 11.

Development trend of value added of marine industry in China from 2001 to 2019

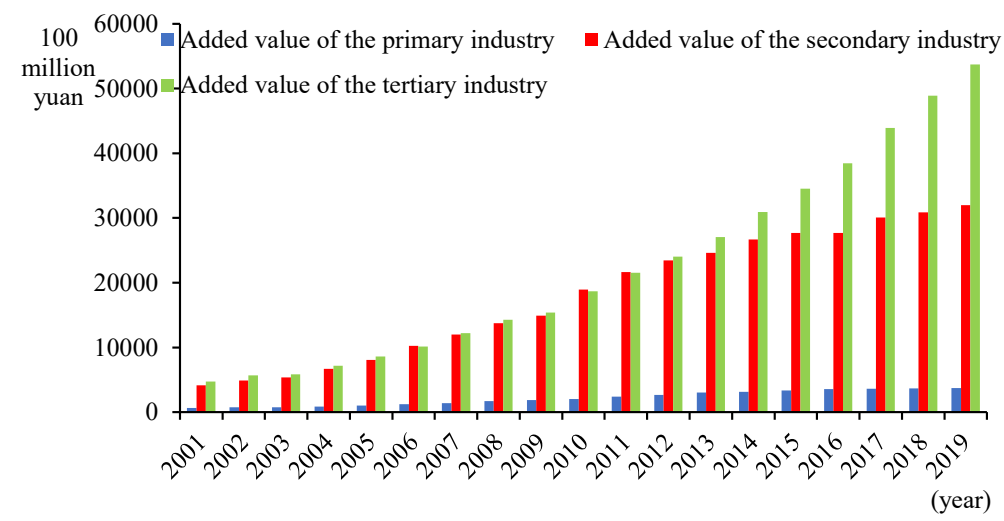

Source(s): China Ocean Statistics Yearbook (2002-2017); China Marine Economic Statistics Bulletin (2017-2019)

\subsection{Traditional marine industry and emerging marine industries}

From 2001 to 2019, an overall fluctuating downward trend has been shown in the proportion of traditional marine industries in Gross Ocean Product, which was from 37.45\% in 2001 to $34.66 \%$ in 2019 (Figure 12), and its proportion was more based on the over-reliance on natural resources and the quantitative advantage of traditional industries; however, the problems of resources, environment, technology and production faced by China's traditional marine industry remain outstanding in recent years. At present, the existing conditions cannot fully meet the requirements of the traditional marine industry in terms of required innovation in practice. How to realize the re-upgrading of the traditional marine industries is a crucial problem to be addressed for the good of the further development of China's marine economy.

The proportion of China's emerging marine industry in Gross Ocean Product shows a tendency to grow, rising from $3.07 \%$ in 2001 to $5.29 \%$ in 2019 (Figure 12), but the added value ratio in this industry remains low, at far below the added value ratio in the traditional industry. This was affected by many factors: firstly, China's emerging marine industry started late, the foundation was weaker than that in other developed countries. There was still a certain lag in production techniques. Second, the relevant national policies were not clearly defined: for example, in the marine biomedical industry, the vague focus of development and the lack of funds led to slow development of the overall industry. Finally, the coastal distribution of early heavy chemical industry and extensive marine development mode in some areas have resulted in enormous pressure on resources and environment and affected the sustainable development of strategic emerging industries, but it is undeniable that China's emerging marine industry has huge potential and ample scope for development. In the future, the development of China's marine economy should focus on science and technology, improve resources carrying capacity and avoid excessive marine industry stagnation in old ways of working.

\subsection{Marine advantage for traditional industries}

Marine advantages for traditional industry are seen in traditional marine industries that exploit their comparative advantages and transform them to their own core competitiveness. The characteristics thereof are rich marine resource endowment, large-scale economic effects, higher industrial growth rates and industrial correlation. Considering factors such as China's marine resource endowment, industrial contribution and level of industrial development, 


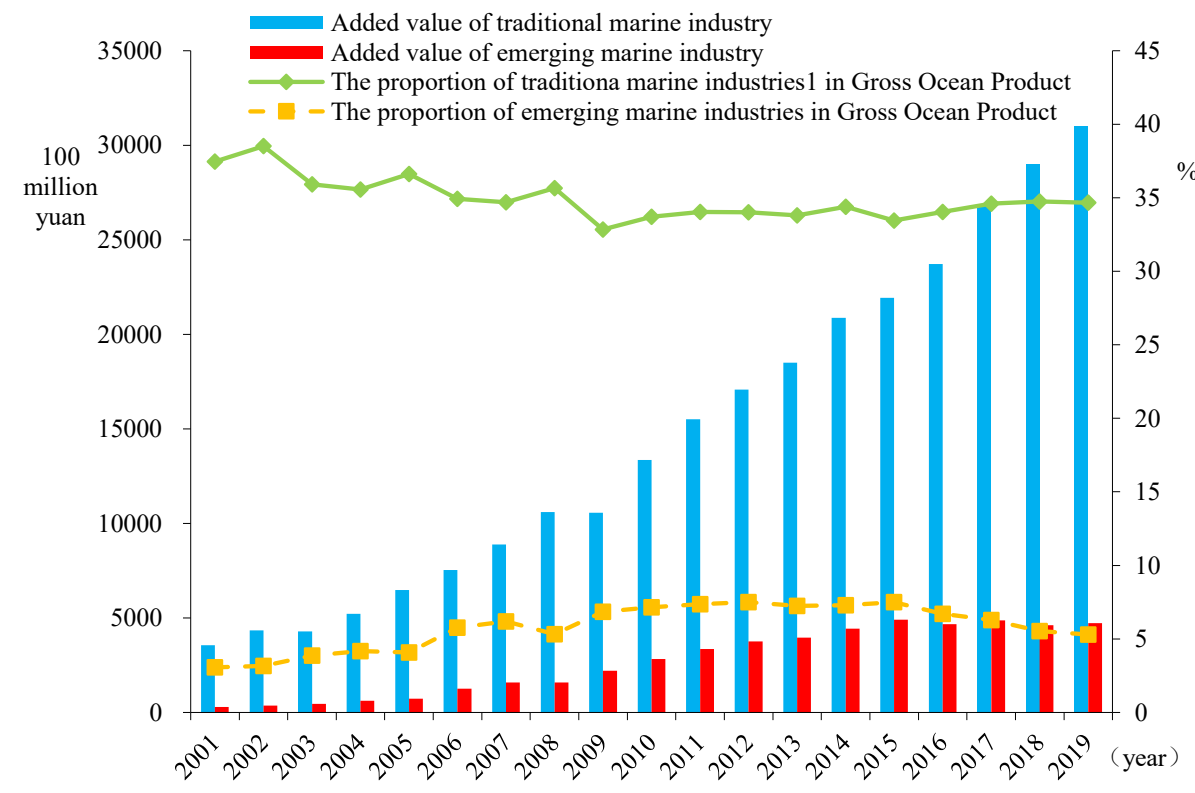

Source(s): China Marine Statistics Yearbook (2002-2017); China Marine Economic Statistics Bulletin (2017-2019)

China's marine traditional industries cover the early development of marine fisheries, marine transport and tourism in coastal areas which has accounted for an increasing proportion of major marine industries in recent years, according to the current development status of various traditional sectors.

Owing to China's superior natural geographical environment, a series of tourist attractions and tourist sites have been formed in coastal areas. The added value of tourism in coastal areas increased from 107.2 billion yuan in 2001 to 1808.6 billion yuan in 2019. Up to 2019, it accounted for 50.63\% of China's major marine industries (Figure 13) and has become an important part of China's major marine industries. The COVID-19 pandemic had a huge impact on the tourism industry in China: many coastal scenic areas were closed down, the number of tourists plummeted and the added value of our country's coastal areas tourism industry declined in 2020 . However, based on the growth trend in tourism in coastal areas in recent years and its proportion in China's major marine industries, it can be predicted that tourism development in coastal areas in the future will recover to, or even exceed, levels enjoyed before the pandemic. In addition, in the process of expanding the scale and increasing the proportion of the industry, there are still some problems to be solved, such as the worsening of pollution, the overloading of operations of various facilities and so on, in coastal areas.

Convenient conditions for the development of China's marine transport industry are provided by the tortuous and long coastline and the concentrated ports along the coast. China's marine transport industry has developed rapidly: the added value of the industry has shown an overall upward trend, from 131.64 billion yuan in 2001 to 642.7 billion yuan in 2019 . Except for the effects of the global financial crisis in 2009, China's marine transportation
China's marine economy development

Figure 12.

Traditional Marine Industry and emerging marine industry from 2001 to 2019 


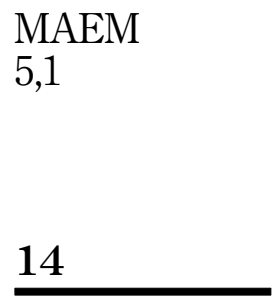

Figure 13.

Tourism and its proportion in major marine industries in Binhai from 2001 to 2019

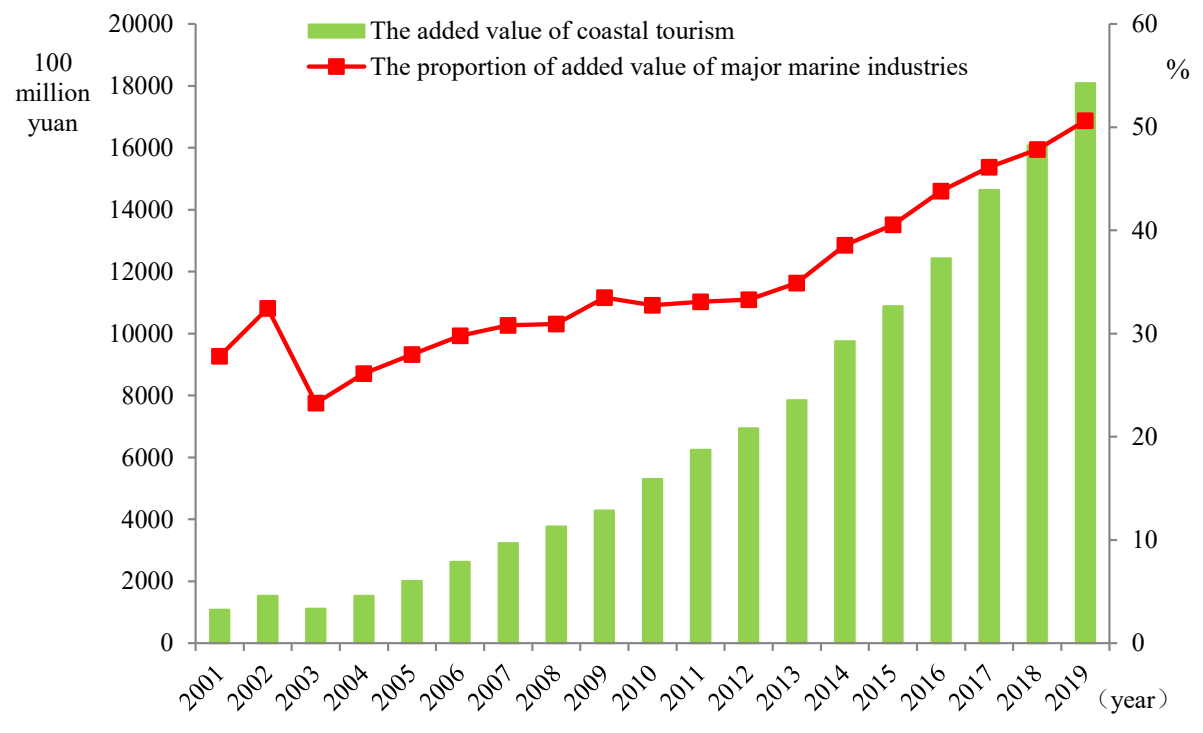

Source(s): China Marine Statistics Yearbook (2002-2017); China Marine Economic Statistics Bulletin (2017-2019)

industry economy has shown steady growth in other years although there remain some problems with its development. The proportion of this industry in the main marine industry decreased from $34.13 \%$ in 2001 to $17.99 \%$ in 2019 (Figure 14). This finding showed that the competitiveness of China's marine transportation industry in the major marine industries was declining, which might be ascribed to the inadequacy of government support and the frequency of natural disasters and man-made accidents.

\subsection{Marine strategic emerging industries}

Marine strategic emerging industries involve production and service activities that fully and reasonably exploit marine resources implemented by the state. The high and new technology is taken as the guidance and industrialization of marine technological achievements as the ultimate goal. Marine strategic emerging industries demonstrate the characteristics of a technological orientation, low consumption of resources, long-term development, linkage of industrial sectors and great prospect. These industries are seen as an indispensable core industry for China to develop blue economy and participate in the international marine economic market. Marine strategic emerging industries include the marine biology industry, marine energy industry, marine manufacturing and engineering industry, marine water utilization industry, marine transportation industry, marine tourism industry and deep-sea energy industry. They involve medicine, aquaculture, transportation, manufacturing, tourism, energy and other fields and are of great strategic and practical significance to the development of marine economy, and its characteristics determine its high-tech content, low energy consumption and strong development potential advantages.

As the core area of competition among countries in the world today, the marine biomedical industry is an important component of China's emerging marine industry. The level of development of a marine biomedicine industry has become an important index to measure the 


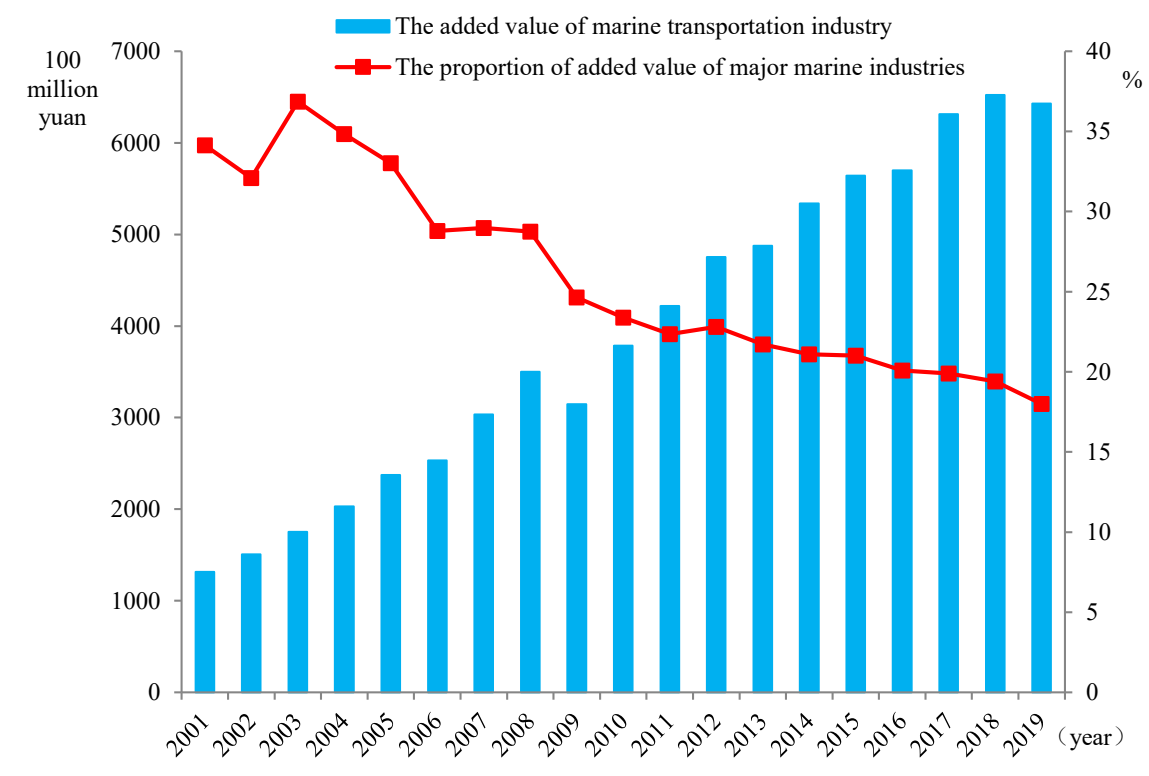

Source(s): China Marine Statistics Yearbook (2002-2017); China Marine Economic Statistics Bulletin (2017-2019)

development of national marine-related industries. The added value of China's marine biomedical industry increased from 570 million yuan in 2001 to 44.3 billion yuan in 2019 . The proportion of major marine industries was increasing steadily, and the industry should develop well in the future (Figure 15). Although the overall level of China's marine biomedical industry has improved since 2001, the proportion of marine biopharmaceutical industry in China's major marine industries remained low due to the limitations of a low industrial development basis, high capital investment requirement and long recovery time: up to 2019, its highest proportion was only $1.24 \%$.

Facing the difficulties of low per capita resource possession, low domestic water and insufficient drinking water supplies in offshore areas, how to realize the comprehensive utilization of seawater becomes the key to solve these problems. Since the beginning of the 21 st century, China's seawater utilization industry has been developing well, the added value thereof increased from 110 million yuan in 2001 to 1.8 billion yuan in 2019, and its proportion in the added value of major marine industries has also shown an overall upward trend (Figure 16). However, the proportion of seawater utilization in the main marine industries remained low, so government should strengthen the support of corresponding encouraging policies to promote the steady development of seawater utilization in China.

\subsection{Level of industrialization of the marine industry}

The Hoffman coefficient is often adopted to measure the degree of industrialization of a country or region's economic development. It is the ratio of the net output value of the consumption data industry sector to the net output value of the capital data industry sector. In this report, the marine light industry sector and heavy industry sector are used to replace consumption-related data pertaining to the industry sector and capital data industry sector
China's marine economy development

Figure 14.

China's marine transportation industry and its proportion in major marine industries from 2001 to 2019 
\begin{tabular}{l} 
MAEM \\
5,1 \\
$\mathbf{1 6}$ \\
\hline
\end{tabular}

Figure 15.

China's marine biomedical industry and its proportion in major marine industries from 2001 to 2019

Figure 16.

Data of seawater utilization and its proportion in major marine industries in China from 2001 to 2019

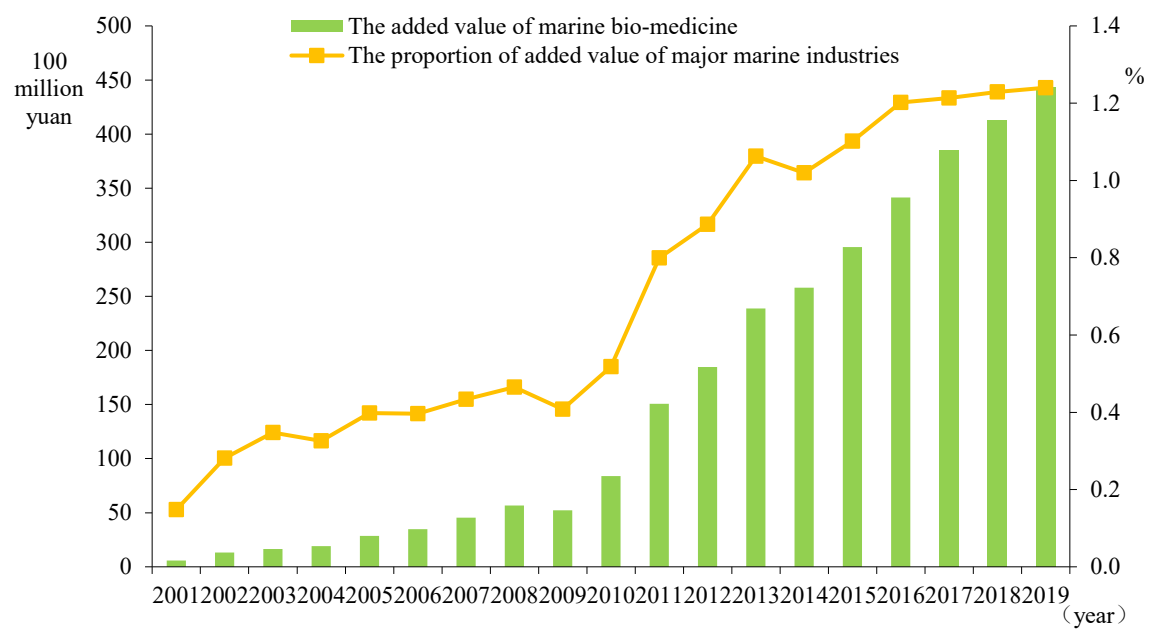

Source(s): China Marine Statistics Yearbook (2002-2017); China Marine Economic Statistics Bulletin (2017-2019)

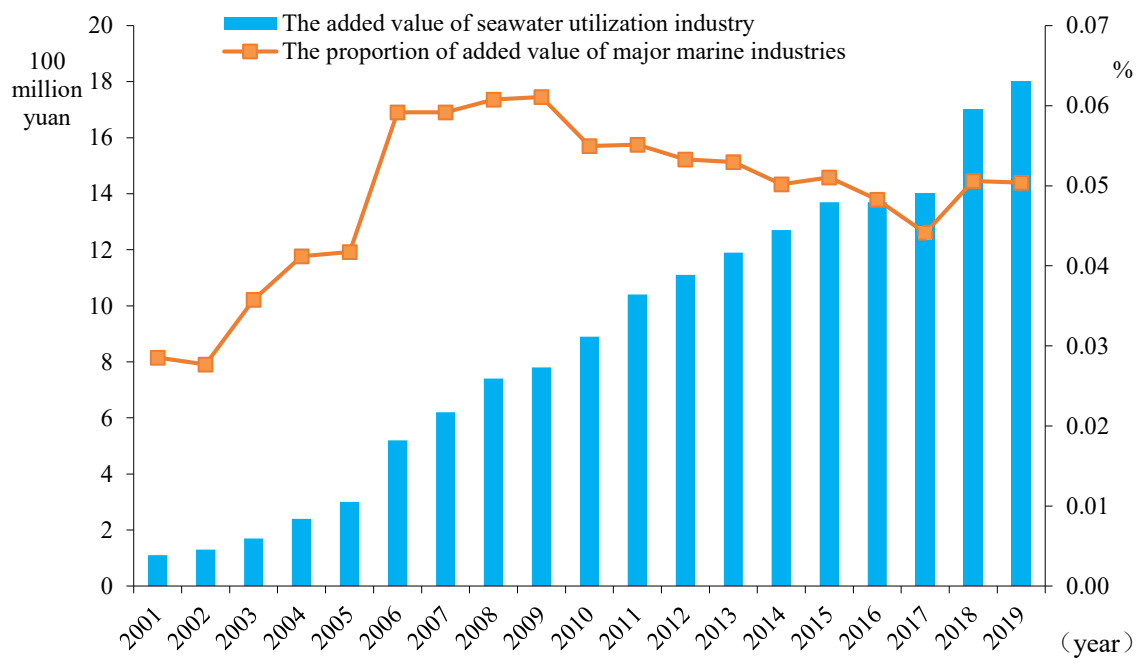

Source(s): China Marine Statistical Yearbook (2002 to 2017); China Marine Economic Statistical Bulletin (2017 to 2019)

respectively to calculate the Hoffman coefficient of China's marine industry. The marine light industry sectors are defined as the marine fisheries sector and marine salt sector in terms of sectoral functions and data availability. The marine heavy industry sectors are represented by the marine ship industry sector, the marine chemical industry sector and the marine biomedical industry sector. 
From 2002 to 2019, the Hoffman coefficient of China's marine industry showed an overall decreasing trend, indicating that the proportion of light industry in China's marine economic sector was gradually decreasing, and the trend of heavy industrialization of marine industry was obvious. This is line with China's transition from "Labor-intensive, resource-extensive" to "Capital-intensive, technology-oriented". From 2002 to 2003, the Hoffman coefficient of China's marine industry was between 4 and 6 , indicating that the development of China's marine industry was in the first stage of the industrialization process, the degree of development of the consumption data industry represented by the marine light industry sector was much higher than that of the capital data industry represented by the marine heavy industry sector. From 2004 to 2010, the Hoffman coefficient of China's marine industry was between 1.5 and 3.5, and it showed a continuous downward trend. The deepening of heavy industry indicated that China's marine industry has entered the second stage of the industrialization process, but the scale of development of China's marine light industry was still far larger than that of marine heavy industry, the Hoffman coefficient fluctuated frequently within the range of 1-2. During this period, the speed of development of China's marine heavy industry was relatively slow, and the unbalanced development of China's marine heavy industry was still problematic (Figure 17).

\section{Environmental analysis of marine economic development in China from 2019 to 2020}

The development of China's marine economy benefits from the continuous advancement of economic globalization and international industrial division. Under the guidance of General Secretary Xi Jinping's concept of marine destiny community, our cooperation with neighboring countries on the basis of oceans is increasingly close. With the continuous advancement of industrial structure transformation, China's technology research and development capabilities, industrial synergy, land and sea-based coordinated development are constantly enhanced, and the integration of marine economy in the macro-economy is continuously improved.

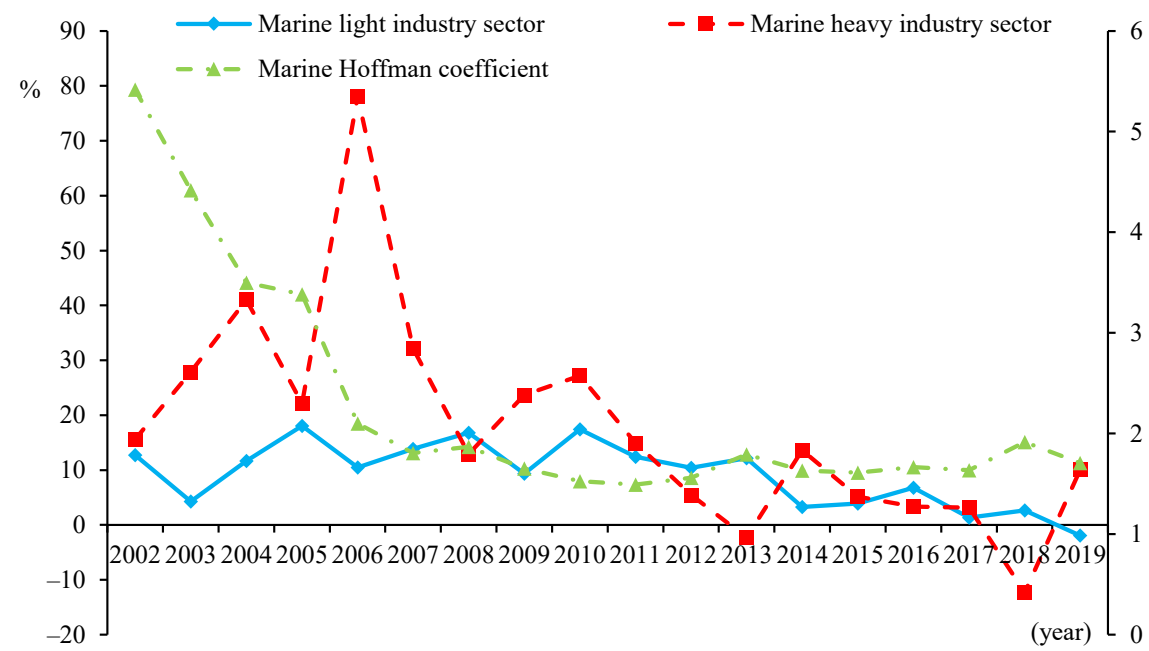

Source(s): China Marine Statistical Yearbook (2002 to 2017); China Marine Economic Statistical Bulletin (2017 to 2019)

China's marine economy development

Figure 17. The growth rate of China's marine industry sector and its Hoffman coefficient from 2002 to 2019 
MAEM

5,1

18

Meanwhile, it is also noteworthy that the uncertainty of the international and domestic development environment poses challenges to marine economic development. Slowing global economic recovery, rising protectionism and increasing competition for marine rights, and global warming and frequent marine disasters seriously restrict the future development of China's marine economy. The outbreak of the new coronavirus pandemic has significantly affected the global economy and brought great challenges to the smooth operation of China's marine economy.

\subsection{Analysis of the international and domestic economic environment}

China's economic environment has become more complex from 2019 to 2020. Internationally, the global economic development situation has reversed, the pace of economic recovery in major economies has slowed, economic growth has declined significantly, and trade protectionism has intensified. Domestically, the downward pressure on China's economy continues to increase and faces multiple challenges in the economic and financial fields, including the Sino-US trade war, weak real economic demand and inflation. In the first quarter of 2020, the sudden outbreak of the new coronavirus pandemic spread globally, which exerts a significant influence on global economic operations. How to make use of marine development policy, optimize the level of marine development and utilization and implement the work of "Six Stability" and "Six Security" is the key to stabilizing the basis of the marine economy and create a new environment for development.

3.1.1 International macroeconomic environment. From 2019 to 2020, the overall global macroeconomic development showed a weak trend. The US economy continued to slow after its 2018 recovery. The Federal Reserve's monetary policy, after raising interest rates and reducing its balance sheet, involves gradually stopping raising interest rates and restarted the economic stimulus of interest rate reduction and balance sheet expansion. Meanwhile, the weak manufacturing industry, low inflation, unclear global trade environment and the impending election all make the US economy full of uncertainty. The eurozone's economic performance has been its worst since 2013. Although the ECB continues to maintain a loose monetary policy, it is still difficult to reverse the current situation of sustained weak economic growth and inflation in the eurozone. The growth of the private sector in the eurozone is stagnant; the PMI index continues to decline, and the manufacturing recession intensifies. Due to the trade frictions, Japan's economic exports continued to slump, causing great pressure on the economy. In addition, Japan faces the risk of deflation. Overall, the effect of "Abe-Enomics" is gradually weakening. Although Japan passed a stimulus plan of more than $\$ 200$ billion and a record budget, its economic prospects are still not optimistic. Emerging market countries have maintained some growth momentum over the past year, but the recovery remains slow. Affected by the monetary policies of developed countries, emerging economies generally implement loose monetary policies, and the economic situation showed a relatively good trend at the end of the year.

At the beginning of 2020, countries around the world have ushered in new shocks such as the global spread of new coronavirus pneumonia, the collapse of crude oil prices and the stock market crash under the background of old challenges such as global economic slowdown and trade friction. Up to now, the spread trend of new coronavirus pneumonia has become more and more intense. Many countries have declared a state of emergency, and the measures of lockdown of cities and countries have continued, which has caused a fatal blow to the already fragile macro-economy of many countries in the world. Economic growth vanished, recovery is difficult, and the economic risk is increased. Affected by the epidemic, the global economic expectation deteriorates, which affects various capital markets such as energy and stocks. The crude oil price plunged and was once negative; the panic in the global financial market increased rapidly, and the multi-country stock market triggered a circuit-breaker mechanism. Old challenges and new shocks add uncertainty to the world macroeconomic environment in 2020, which bring great challenges to employment and market players. 
3.1.2 The domestic macroeconomic environment. From 2019 to 2020, China's macroeconomy is facing a more complex external environment. Economic growth slowed (on a quarterly basis) and downward pressures continued to increase. In the four-quarters of 2019, China's GDP growth rates were $6.4 \%, 6.2 \%, 6.0 \%$ and $6.0 \%$, respectively. The annual GDP growth rate was $6.1 \%$, which was the lowest since 1990. With the escalating trade war between China and the United States, dozens of Chinese high-tech enterprises such as Huawei are listed on the entity list for reasons such as endangering national security. The United States, together with its Allies, limits related enterprises in raw material supply, market access, technology export and other aspects to curb the development of China's high-tech industry. China is gradually carrying out macro-control of the transformation of old and new sectors. Deleveraging, risk prevention, housing control and other policy factors exert a certain influence on current economic development. Affected by the price of pork, CPI increased by $2.9 \%$ in 2019 compared with the previous year, while PPI was limited by the price of means of production, with a decline of $0.3 \%$.

Under the severe macroscopic situation, the Chinese Government has increased levels of counter-cyclical adjustment and actively implemented the "six stability" policy, so that the national economic growth has basically maintained a reasonable range. In 2019, a total of 13.52 million urban jobs were created nationwide, and the registered unemployment rate in towns across the country was $3.62 \%$, which ensured the basic stability of the labor market. Foreign exchange reserves remained stable and bank balances improved gradually, leaving an annual balance of $\$ 3,107.9$ billion, an increase of $\$ 35.2$ billion since the beginning of the year.

In the first quarter of 2020, the new coronavirus had a significant effect on China's national economy: GDP fell 6.8\% year-on-year, and the rates of growth in investment and consumption dropped sharply, falling into negative growth (i.e. shrinking). The export trade balance changed from surplus to deficit. Meanwhile, the pandemic has affected industries and the service sector, and a large number of normal production and operation activities have been stopped. Manufacturing and non-manufacturing PMI created a new historical low, while CPI continued to be at a high level of more than $5 \%$ under the influence of epidemics, pork prices and seasonal disturbances: real economic demand was significantly weak. With the gradual control of the domestic epidemic at the end of the first quarter, the impact thereof on economic activities will gradually weaken, but the global spread as a pandemic will affect the improvement of the domestic macro-environment. The implementation of domestic reproduction policy will determine the overall trend of China's economy in 2020.

3.1.3 International economic layout and game. 3.1.3.1 United States economic security strategy. The US "National Security Strategy Report" clearly raised economic security to the height of national security. This reflects the US's emphasis on its own economic strength and its tendency to absolutize the US national interests in the international economic order. The report shows that economic prosperity is an important pillar of the US national security and emphasizes that technological innovation and energy industry advantages are the foundation of the US economic security, with the intention of reshaping the dominant position of the United States in the international economic order.

Indeed, since the Trump administration took office, US economic unilateralism has become more visible. Since 2017, the Trump administration has bypassed the WTO dispute settlement mechanism and relied on domestic bills enacted in the United States to conduct unilateral trade investigations on several major economies in the world, including China and Allies of the United States, and unilaterally adopted protectionist trade measures, including substantially increasing tariffs and setting trade barriers. In addition, the United States has repeatedly withdrawn or boycotted the existing multilateral international mechanisms, such as the withdrawal of the TPP agreement, boycott of the new rules of

China's marine economy development 
MAEM

5,1
WTO negotiations, unilateral requirements to restart "North American Free Trade Association" and so on.

The Trump administration's "America First" orientation and its unilateralist national economic security strategy have brought great uncertainty and risks to the global economy. The global economic order will gradually transform into conservative realism, and the negotiation of international trade rules will be more difficult, thus deteriorating the international trade and international investment environment. China, a focus of policy-leaders in the US, will face more tariff barriers in the future, the development of China's high-tech industry will be suppressed by the US in the name of intellectual property protection and national security, and China's counterpart investment will face more restrictions. At the same time, China needs to guard against US pressure on Allies to impose further trade restrictions on China and US rallying of China's neighbors to cause friction with China on its land and sea borders.

3.1.3.2 EU 2020 strategy. The EU 2020 strategy proposes three strategic priorities, five quantitative objectives and seven supporting flagship plans. The EU 2020 strategy is a reform strategy under the background of its weak economic recovery and the prominent problem of the Lisbon Strategy. The new development strategy emphasizes the leading role of science and technology and innovation in social and economic development. Under the guidance of this strategy, the future economic development of the EU will mainly focus on the intelligent economy dominated by knowledge and innovation, achieving sustainable development, improving employment levels and strengthening social cohesion by improving energy efficiency.

3.1.3.3 Russian Arctic strategy. Under strategic opposition from NATO led by the United States, Russia has sought new strategic fulcrums in the direction of the Arctic and has carried out energy development, waterway construction and military deployments therein. In recent years, Russia has issued several documents indicating attachment of great importance to Arctic energy sources at a strategic level, actively promoting its multilateral Arctic energy development projects and has built large-scale energy development support facilities to promote social and economic development through energy development. At the same time, Russia continues to accelerate the construction of the northern waterway and clearly declares its sovereignty thereof, which has a certain effect on the passage of other ships. Russia also actively deploys all-round, three-dimensional military forces in the Arctic region to build its absolute military advantage therein.

3.1.3.4 Regional economic strategy of Japan. After the Second World War, Japan actively promoted the Asia-Pacific economic strategy and the East Asian regional economic strategy and will join the TPP as the key to its dominant position in Asia-Pacific and East Asia. After the Trump administration announced its withdrawal from the TPP and actively implemented the conservative policy of "America First"; Japan remains engaged in the TPP and actively draws other participating member countries to revive the TPP to dilute China's influence in the Asia-Pacific region. Second, Japan invested heavily in promoting high-standard cooperation projects of regional comprehensive economic partnership agreements, highlighting its strategic position of cooperation with ASEAN countries, forming competition with China in terms of East Asian cooperation.

3.1.3.5 New measures for China's participation in the global economy. Under the background of the global economic order gradually turning to conservative realism and the rise of economic anti-globalization, China actively promotes the process of economic globalization. From the perspective of strengthening international economic cooperation and maintaining the healthy development of domestic economy, the $\mathrm{CPC}$ has conducted a strategic plan for the integration of the world economy and the Asia-Pacific economy. General Secretary Xi Jinping proposed a vision for the global values of the community of shared future for mankind at the 18th National Congress, giving China's answer to the peaceful development of the world and pointing out the direction in which China could 
participate in the global economy. China has actively proposed "The Belt and Road Initiative" relying on existing bilateral and multilateral mechanisms and together with the countries along the border to create political mutual trust, economic integration, cultural inclusion of interest communities, future communities and responsible communities. As of November 2019, the Chinese Government had signed 197 intergovernmental cooperation agreements with 137 countries and 30 international organizations, opening a new model for regional cooperation. China has actively implemented the free-trade zone strategy and has signed 17 free-trade agreements with 25 countries and regions. In 2019, China participated in promoting the "Regional Comprehensive Economic Partnership Agreement", China-Japan-South Korea FTA negotiations, and regional economic cooperation has achieved remarkable results. In addition, to promote trade liberalization and facilitation, China has also vigorously promoted the construction of domestic free-trade zones. At present, 18 free-trade zones have been approved and fully covered by China's coastal provinces.

\subsection{Marine economic policy and the legal environment}

3.2.1 Marine economic policy environment in China. Around the national overall planning structure, supporting the development of the marine economy and promoting the construction of marine power, many marine economy and marine science and technology plans have been issued in the field of oceans.

During the 13th Five-Year Plan period, the State Oceanic Administration and the National Standardization Administration jointly issued "National Ocean Standardization '13th FiveYear' Development Plan" and "The 13th Five-Year Special Plan for Scientific and Technological Innovation in the Marine Field".

In December 2016, "National Science and Technology Plan (2016-2020)" pointed out the long-term mechanism of innovation-driven development of science and technology in China. In February 2018, "National Marine Ecological Environment Protection Plan (2017-2020)" established four marine objectives and development principles. In September 2018, "Implementation Opinion on Promoting High Quality Development of Marine Economy" will focus on supporting the development of marine emerging industries and other sectors, accelerating the construction of the marine economic circle. In November 2018, "Notice on the Construction of Marine Economic Development Demonstration Zone" specified the overall objectives and main tasks of the construction of 14 demonstration zones. In December 2018, "Intelligent Ship Development Action Plan (2019-2021)" is aimed at forming a top-level plan for the development of intelligent ships in China. In January 2019, the National Bureau of Statistics approved the "Gross Ocean Product Accounting System", which provides a more scientific and accurate measurement method for the scale and structure of China's marine economy. In June 2019, "Construction Plan of National Marine Ranch Demonstration Zone (2017-2025)" proposed the creation of 200 national marine ranching demonstration zones. In April 2020, the "Marine Economic Statistical Survey System" and "Gross Ocean Product Accounting System" were implemented.

3.2.2 Regional Marine economic policy environment in China. As of July 2020, China has formed three national marine economic demonstration zones: the Shandong Peninsula Blue Economic Zone, Zhejiang Marine Economic Development Demonstration Zone and Guangdong Marine Economic Comprehensive Experimental Zone, and the three demonstration zones have issued detailed marine economic support policies.

Shandong Province currently focuses on accelerating the transformation and upgrading of the traditional marine industry. "Marine Development Plan of Shandong Province (20152020)" predicts that by 2020, the proportion of the marine economy in the total GDP of the province will reach more than $23 \%$. "Development Plan of Marine Economy in Shandong Province" points out that by 2020, Gross Ocean Product will grow by more than $10 \%$

China's marine economy development 
MAEM

5,1

annually, and marine science and technology will contribute more than $70 \%$ to the marine economy.

"Zhejiang Modern Marine Industry Development Plan (2017-2022)" suggests that by 2022 , the comprehensive strength and quality benefit of the modern marine industry in the province will be further improved, and the construction of a strong marine province has taken a solid step. "13th Five-Year Plan for Marine Port Development in Zhejiang Province" made it clear that by 2020,51 berths of more than 10,000 tons capacity will be added to the coastal ports of the whole province, with a total of 270 berths, so as to improve the radiation driving capacity of the port economic circle. The "13th Five-Year Plan for Marine Ecological Environment Protection in Zhejiang Province (2016-2020)" states that, by 2020, the quality of seawater in coastal waters remained stable, and 10 demonstration zones for marine ecological construction at or above the provincial level were established. The proportion of the designated marine ecological red line area in the total area of the province's sea area was not less than $30 \%$.

Guangdong Province proposes to focus on the construction of some concentrated and intensive sea areas, marine industrial agglomeration areas and coastal economic new areas to build a new pattern of marine economy. The "13th Five-Year Plan for Marine Economic Development in Guangdong Province” proposes to build "One Belt, Six Bays, Five Islands Group", "Three Districts, Three Circles, Two Bases" and "Characteristic Marine Industry Carrier" according to the requirements of land and sea coordination, cluster development and their optimized layout. "Guangdong Marine Ecological Civilization Construction Action Plan (2016-2020)" proposes that, by 2030, the goal of building a beautiful marine ecological civilization of "clean water, green shore, clean beach, bay beauty, abundance, and harmony between people" will be realized. A "Three-year Action Plan for Six Major Marine Industries in Guangdong Province" pointed out that it should focus on supporting the development of high-end marine equipment, offshore wind power, marine biology and another six industries.

3.2.3 The legal system governing China's marine economy. To safeguard marine sovereignty and ensure the development of marine undertakings, China has promulgated many marine-related laws and established a good marine legal environment. In February 2016, the Nineteenth Meeting of the Standing Committee of the Twelfth National People's Congress of the People's Republic of China adopted "Law of the People's Republic of China on Exploration and Development of Deep Seabed Resources", which is of great significance to regulate the activities of Chinese citizens, legal persons, or other organizations in the exploration, development and investigation of deep seabed resources. The National People's Congress amended "Maritime Traffic Safety Law of the People's Republic of China" in November 2016, "Customs Law of the People's Republic of China" and "Marine Environmental Protection Law of the People's Republic of China" in 2017, improving the marine legal system and strengthening the legal guarantee related to oceans. In January 2017, the State Oceanic Administration issued "Measures of coastline protection and utilization management" to strengthen the protection and utilization management of coastline, achieve the goal of natural coastline ownership control and construct a rational natural coastline pattern. At the third meeting of the Standing Committee of the National People's Congress in June 2018, the decision on the exercise of maritime rights protection and law enforcement authority by China's maritime police was adopted, which standardized the tasks and powers of the Maritime Police Bureau. In January 2019, the Ministry of Agriculture and Rural Affairs, the Ministry of Ecological Environment, and the Ministry of Natural Resources provided some suggestions pertaining to accelerating the green development of aquaculture, so as to solve the problems of unreasonable aquaculture layout and industrial structure in some regions and high aquaculture density in others. 
3.3 Analysis of sea resources and technological environment

3.3.1 Current status of marine resources and their environment in China. China is a major maritime country with a coastline of about $18,000 \mathrm{~km}$, spanning the South China Sea, the East China Sea, the Bohai Sea and many other seas and covering an area of more than 4.7 million square kilometers of inland and offshore waters. The natural deep-water line is more than $400 \mathrm{~km}$ offshore, and tidal flats amount to 38,000 square kilometers. The vast sea area and many islands provide sufficient resources for the development of China's marine economy.

Marine mineral resources include oil, natural gas, gold, copper, limestone and other minerals. Chemical resources consist of bromine, magnesium, potassium and other chemical elements; Energy resources include offshore wind power, tidal power and so on. China's offshore oil resources amount to about 24 billion tons with some 14 trillion cubic meters of natural gas. Theoretical reserves of marine renewable energy amount to 630 million kilowatts.

In terms of marine biological resources, China has more than 20,000 kinds of marine creatures, including more than 3,000 kinds of marine fish. China's offshore fishing areas cover an area of 280 million hectares, which are divided into the Bohai Sea, the Yellow Sea, the East China Sea and the South China Sea. Among them, the total area of fishing grounds in the four marine areas amounts to 77,000 square kilometers, 380,000 square kilometers, 770,000 square kilometers and 3.5 million square kilometers, respectively.

In terms of coastal tourism resources, China has more than 11,000 islands, with the total island area accounting for about $0.8 \%$ of China's total land area. By the end of 2017, there were 1,028 confirmed natural landscapes, 775 cultural landscapes, 72 bathing beaches and 25 $5 \mathrm{~A}-$ level island-related tourist areas on the country's islands.

3.3.2 Marine science and technology development in China. Under the guidance of the policy associated with being a maritime power, the coverage of marine science and technology in China has gradually expanded, the areas involved have gradually expanded, and the transformational capacity of scientific research has gradually improved. The environment for the development of marine science and technology has become clearer.

3.3.2.1 General survey of marine scientific research projects. In 2016, the country completed 18,139 marine research projects, 16,016 research papers and 369 research works (see Table 1).

3.3.2.2 Ocean-related research institutions and personnel. In 2016, the number of China's marine scientific research institutions reached 160, with 29,258 employees, of which $26.40 \%$ were $\mathrm{PhD}$-qualified, $29.26 \%$ were masters-level-qualified, $23.45 \%$ were college students, and $5.70 \%$ were junior college students (see Table 2).

3.3.2.3 Funding income of marine scientific research institutions. The "Global Ocean Technology Innovation Index Report" shows that China's Ooean technology innovation index increased year-on-year, reaching 67.3 in 2017, successfully jumping from the third echelon to the second echelon. In 2019, China's marine science and technology innovation index ranked No. 5, among which innovation output and innovative applications ranked among the top two in the world. In 2016, the total scientific and technological funding of marine scientific research institutions reached 24.988 billion yuan and the funding income of marine scientific research institutions in Beijing, Shanghai and Shandong ranked among the top three in the country (see Table 3).

3.3.3 Marine high-tech development environment. The basic environment for marine hightech research and development has been significantly improved. In recent years, China has gradually formed a multi-dimensional and three-dimensional basic pattern of marine hightech research and development. In terms of oceans, the construction of marine scientific research ships has greatly improved ocean observation, detection and prediction capabilities, and the continuous breakthroughs in deep-diving equipment have more deep-sea development possible. In the north and south Polar Regions, China has several scientific
China's marine economy development

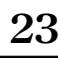


MAEM

5,1

\section{4}

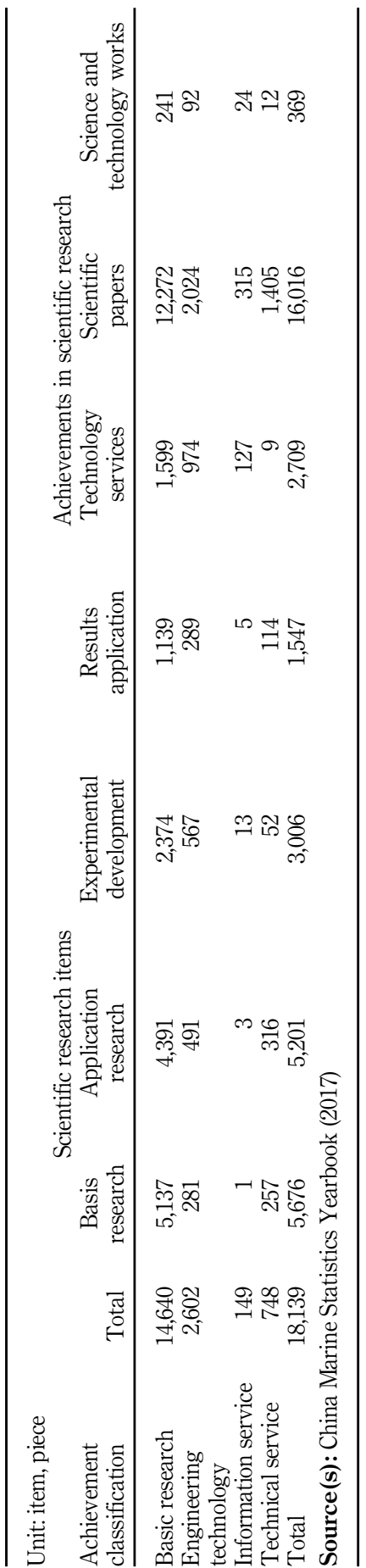

Table 1.

China's marine science and technology R\&D achievements in 2016 


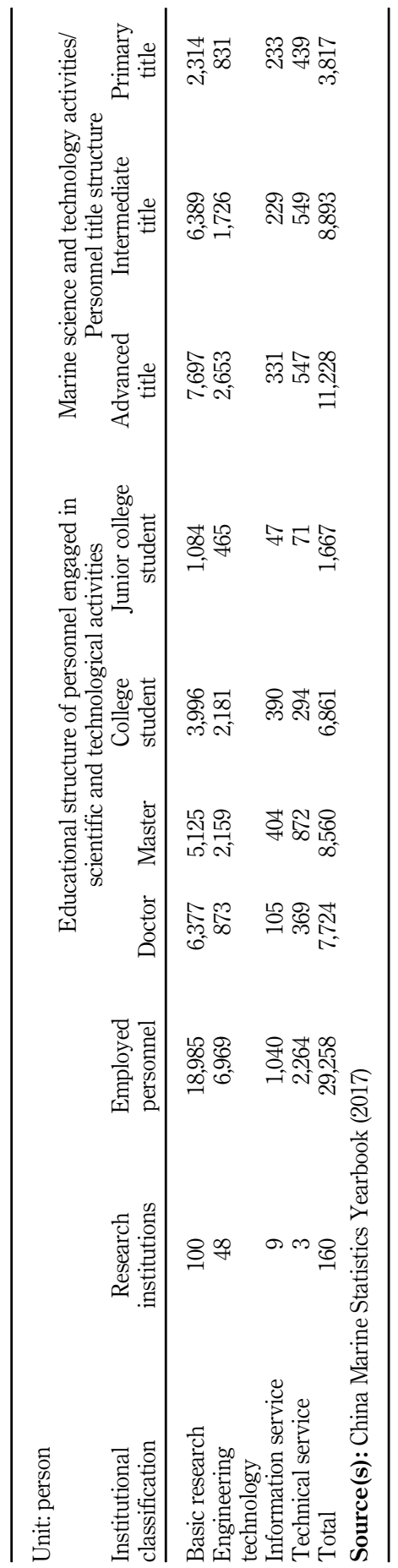

China's marine economy development

25

Table 2. Structure of China's marine research institutions and personnel in 2016 
MAEM

5,1

\section{6}

research stations such as the Great Wall Station, Zhongshan Station, Kunlun Station and the Yellow River Station. They are of great significance to China's research on climate, environment, mineral resources and biological resources. In space, five ocean one satellites and a Sino-French marine satellite monitor the marine environment in real-time and provide support for the maintenance of marine rights and interests, marine resource development, marine environmental protection, marine scientific research and national defense construction.

The direction of the marine high-tech policy is clear. In recent years, the state has attached great importance to the development of marine high-tech industries and has successively approved eight national high-tech industrial bases to build marine high-end equipment manufacturing, marine medicine and biological products, marine biological breeding and healthy breeding, seawater utilization, marine high-tech services, etc.

Marine high-tech financial support is strong. In February 2018, the "Guiding Opinions on Improving and Strengthening Financial Services for Marine Economic Development" required active exploration of innovative investment and financing systems and models in the marine sector, increasing financial support and improving financial services. During the "13th Five-Year Plan" period, China strives to provide about 100 billion yuan of intentional financing support to the marine economy.

International cooperation in marine high-tech has been continuously strengthened. In recent years, China and others nations have established China-Indonesia, China-Sri Lanka, China-Pakistan and other national-level overseas joint research centers and laboratories with countries along the "Belt and Road" and established joint marine observatories such as Babi and Bitong. The collaborations include marine environmental monitoring and refined forecasting, marine disaster prevention and mitigation, marine ecological protection, marine aquaculture, seawater desalination and many other aspects. These international collaborations have greatly enhanced the innovation and international influence of China's marine science and technology base.

\section{Analysis of China's marine economic development issues from 2019 to 2020 4.1 The necessity of marine economic development model optimization}

Marine economic development in China has made significant progress, but the long-standing development model of extensive predatory development and pollution-first treatment has led to marine environmental pollution, waste of marine resources and marine ecological degradation prominent problems. With the development of the marine industry, a large amount of waste water from the marine aquaculture industry and terrestrial waste is discharged, causing an increasingly serious problem of eutrophication of water bodies. In 2019, a total of 38 red tides were found in China's seas with a cumulative area of 1991 square kilometers. The marine fishing supervision system is imperfect and preventative measures are not in place; overfishing has led to the continuous decline of fishery resources; seafood

Table 3.

Revenue of marine research institutions in China's coastal areas in 2016

\begin{tabular}{lccccccc}
\hline $\begin{array}{l}\text { Unit: } 100 \text { million RMB } \\
\text { Region }\end{array}$ & Beijing & Tianjin & Hebei & Liaoning & Shanghai & Guangxi & Hainan \\
\hline Total fund income & 65.06 & 15.92 & 2.39 & 17.73 & 37.77 & 1.42 & 1.59 \\
\hline Region & Jiangsu & Zhejiang & Fujian & Shandong & Guangdong & Other & Total \\
\hline $\begin{array}{l}\text { Total fund income } \\
\text { Source(s): China Marine Statistics Yearbook (2017) }\end{array}$ & $\begin{array}{c}12.91 \\
7.82\end{array}$ & 36.07 & 29.19 & 9.73 & 249.88 \\
\hline
\end{tabular}


processing procedures are basic, efficiency of resource utilization is low; marine renewable energy development, comprehensive utilization of seawater, marine biomedicine and key core technologies of other industries are insufficiently innovative and stable. The production capacity is relatively low, and the construction of national and industry standards is lagging; the development of marine mineral resources is inefficient, and the benefits accrued therefrom are not high. Large oil tankers and oil platforms continue to increase, and the risks of collisions, oil spills and other water traffic accidents increase. To expand the blue economic space and realize the green and sustainable development of the marine economy, the development model of the marine economy must be optimized and the high-quality development of the marine economy promoted.

\subsection{Marine economic regulation and management capabilities need to be improved}

With the gradual increase of maritime awareness in coastal provinces and cities, China's marine economic construction has continuously made new progress. However, there are some shortcomings in the development process. First, the development of traditional industries is hindered. China's traditional marine industry is facing outstanding problems such as damage to the ecological environment, difficulty in obtaining relevant talents, extensive development and less advanced levels of exploitation of key technologies. The existing conditions cannot be allowed to prevail and continue. The requirements of traditional marine industry innovation and practice have caused the proportion of traditional marine industry in total marine production to fluctuate and decline from 2001 to 2019; second, the development of traditional and emerging industries is not equal. In 2019, traditional marine industry accounted for all marine production. The proportion of the value added by the emerging marine industry is only $5.29 \%$, which is far lower than the proportion accounted for by traditional industries; the third is the slow development of China's marine heavy industry, and the unbalanced development of the light and heavy industries is severe; the fourth is the regional marine industry lacks core competitiveness. In addition, due to the effects of the new coronavirus pandemic, contradictions among countries have become more prominent, China's economic environment has become more complex, trade protectionism has intensified, the Sino-US trade war has escalated, and the development of the marine economy is facing multiple challenges. China's marine economic development has serious problems such as ecological imbalance, uncoordinated, unsustainable development and insufficient risk resistance and innovation, further enhancing the marine economy's industrial structure regulation, risk control, coordination of maritime entities' contradictions and innovation-driven leadership capabilities. It is the only way to innovate and develop new industries in the marine economy, create a new engine for growth and build a new engine for sustainable development.

\subsection{The urgency of improvement of marine economic data statistics}

In recent years, China's marine economic statistics has continuously expanded its scope, supplemented content and improved efficiency through institutional statistics, survey statistics, direct corporate reporting and big-data analysis. However, there are still many problems in actual statistical work, such as insufficient classification of economic statistics. Detailed, incomplete statistical indicators, slower update of marine economic statistics, poor timeliness and delays in data quality control. In addition, the national data and the marine economic statistical indicators and statistical methods of various provinces, municipalities and autonomous regions are not uniform, resulting in poor data comparability. Second, the global statistical coverage of the marine industry is relatively low, especially those pertaining to countries along the "Maritime Silk Road" in the 21st century that need to be supplemented and improved. The exploration, monitoring, evaluation and integration of marine economic
China's marine economy development

\section{(1)}


MAEM

5,1

statistical data will play a vital role in future marine decision-making. The marine economic data statistical system should be continuously improved to improve its completeness, timeliness, comparability and accuracy.

\subsection{The necessity of improvement in marine economic and financial support}

Finance is an important support for the development of the marine economy. The rapid development of the marine economy in the new era, changes in marine economic development models, changes in industrial structure, and improvements in efficiency have continuously increased the demand for capital investment, posing new challenges to the development of financial support mechanisms. First, due to the large amount of capital demand, long cycle and high risk of sea-related enterprises, relevant financial institutions raise concerns when approving credit funds. In addition, the number of sea-related enterprises that choose to list on the main board market and issue corporate bonds for direct financing is small, resulting in insufficient funds for sea-related enterprises and insufficient financial support for industrial development; second, the evaluation of related marine collaterals such as marine intellectual property rights lacks basis, and most marine scientific research enterprises have high labor costs and scientific research costs, and there are problems around low efficiency in the transformation of scientific and technological achievements and the inability to conduct reasonable assessments has increased the difficulty of financing; third, the capital market system is imperfect, marine companies have slower growth, higher risks, and some financial indicators make it difficult to meet current listing standards, thus deterring marine companies from entering the securities market. Fourth, the protection provided by marine insurance cannot meet the needs of sea-related laborers, and the coverage is not sufficiently extensive: most policies are limited to the marine transportation industry and fishery, and the types of insurance product available lack diversity. The development of the marine economy is inseparable from financial support. Accelerating the construction of a maritime power requires strong financial support. To develop the oceans one must first enhance the function of financial services.

\subsection{The necessity of enhancement of response to COVID-19}

The coronavirus pandemic that began in 2019 has had a huge impact on the global economy. Affected by the pandemic, international trade and investment have shrunk; the bulk commodity market is turbulent, and the development of the marine economy has suffered. The coastal tourism industry bears the brunt due to its high sensitivity; because of the ongoing pandemic, government has adopted strict controls over coastal tourism. More than $90 \%$ of coastal areas have been closed, and the number of tourists has plummeted. Many tourism companies have suffered serious losses and cash flow problems. Tensions have resulted in a tourism crisis; the marine transportation industry has also suffered. The lockdown, work stoppages and isolation policies of various countries have greatly reduced marine transportation orders, the number of liners has increased the number of blank sailings, and the cost of marine transportation has increased. Stricter inspection and quarantine have greatly reduced the efficiency of global shipping; after the outbreak, companies across the country ushered in extended holidays, delayed resumption of work, restricted expressways and suspension of public transportation, resulting in a sharp decline in domestic refined oil market consumption. The output value of China's marine oil and gas industry has declined; China's aquaculture industry has not been spared; the consumption of seafood has dropped sharply; the tonnage of imported and exported seafood has plummeted, and the aquaculture industry has suffered heavy losses. The pandemic has affected various industries in China's marine economy. It is necessary to strengthen responses to the epidemic, properly handle the relationship between disease prevention and 
development and adapt to the new normal to maintain the stable and healthy operation of the marine economy.

\section{Forecast of China's marine economic development situation}

Through the research and analysis of the statistical data of marine economy, trend extrapolation methods, exponential smoothing, grey forecasting, simultaneous equation models, neural network methods, and Bayesian vector autoregressive models were used as combined optimization and prediction tools. According to the principle of combination prediction method, Matlab ${ }^{\mathrm{TM}}$ software programming is used to study and predict the development situation of marine economy in China from 2020 to 2022. The predicted results are summarized in Table 4.

From 2019 to 2020, China's marine economy is facing severe international and domestic pressures, which brings great uncertainty to the development of marine economy. Internationally, the novel coronavirus pandemic has spread globally, political and economic frictions and conflicts are on the rise, international trade and investment are shrinking, and the global industrial and supply chains are blocked. Domestically, economic growth has slowed, consumption, investment and exports have declined, while the pandemic has further increased downward pressure on China's national economy. Based on the analysis of the international macroeconomic situation and the actual development of China's economy, it is expected that Gross Ocean Product of China will be around 9,100 billion yuan and the growth rate will be about $2 \%$ in 2020 . The growth rate of Gross Ocean Product in the five major economic zones has slowed, and may even suffer shrinkage, among which the impact on the Bohai Sea Economic Zone and the Yangtze River Delta Economic Zone is large. For traditional industries, the epidemic situation will have a significant impact on marine transportation, marine fisheries and coastal tourism. For emerging industries, the marine shipping industry and seawater utilization industry will be significantly affected.

After the outbreak of the novel coronavirus pandemic, China has somewhat controlled the spread of the disease locally at least in a relatively short period of time, timeously promoted the resumption of labor and steadily promoted China's economic recovery. The short-term outbreak has a great impact on China's marine economy, the efficiency of marine fishery transportation has declined, the coastal tourism industry has been frustrated, and the long-term development of China's marine economy has been subjected to much

\begin{tabular}{|c|c|c|c|c|c|c|}
\hline Predictors & $\begin{array}{l}2020 \text { forecast } \\
\text { Scope of } \\
\text { prediction }\end{array}$ & $\begin{array}{l}\text { Nominal } \\
\text { growth }\end{array}$ & $\begin{array}{l}2021 \text { forecast } \\
\text { Scope of } \\
\text { prediction }\end{array}$ & $\begin{array}{l}\text { Nominal } \\
\text { growth }\end{array}$ & $\begin{array}{l}2022 \text { forecast } \\
\text { Scope of } \\
\text { prediction }\end{array}$ & $\begin{array}{l}\text { Nominal } \\
\text { growth }\end{array}$ \\
\hline $\begin{array}{l}\text { Gross national marine } \\
\text { product }\end{array}$ & $\begin{array}{l}(90,426, \\
91,675)\end{array}$ & $1.1-2.5$ & $\begin{array}{l}(99,613, \\
101,400)\end{array}$ & $9.3-11.3$ & $\begin{array}{l}(105,110, \\
107,400)\end{array}$ & $5.5-5.6$ \\
\hline $\begin{array}{l}\text { Total added value of } \\
\text { marine industry }\end{array}$ & $\begin{array}{l}(58,325, \\
59,130)\end{array}$ & $1.8-3.2$ & $\begin{array}{l}(63,943, \\
66,180)\end{array}$ & $8.8-12.6$ & $\begin{array}{l}(67,734 \\
70,610)\end{array}$ & $5.9-6.7$ \\
\hline $\begin{array}{l}\text { Value added of marine- } \\
\text { related industries }\end{array}$ & $\begin{array}{l}(32,101 \\
32,545)\end{array}$ & $0-1.4$ & $\begin{array}{l}(35,260, \\
35,670)\end{array}$ & 9-10.2 & $\begin{array}{l}(36,840, \\
37,372)\end{array}$ & $4.5-4.8$ \\
\hline $\begin{array}{l}\text { Value added of major } \\
\text { marine industries }\end{array}$ & $\begin{array}{l}(36,132, \\
36,631)\end{array}$ & $1.1-2.5$ & $\begin{array}{l}(39,922, \\
39,940)\end{array}$ & $9.6-9.7$ & $\begin{array}{l}(42,050 \\
42,057)\end{array}$ & $5.2-5.3$ \\
\hline $\begin{array}{l}\text { Value added of marine } \\
\text { scientific research }\end{array}$ & $\begin{array}{l}(22,193 \\
22,499)\end{array}$ & $2.8-4.2$ & $\begin{array}{l}(24,022, \\
26,240)\end{array}$ & $7.4-9.6$ & $\begin{array}{l}(25,678 \\
28,560)\end{array}$ & $6.9-8.8$ \\
\hline
\end{tabular}

China's marine economy development
Table 4.

Forecast of major indicators of the marine economy in China from 2020 to 2022 
MAEM

5,1

uncertainty through affecting maritime trade. Although the epidemic has affected China's marine economy in the short term, China's marine economy has maintained stable growth in recent years, the foundation of economic development is solid, the industrial structure is constantly being upgrading, and the proportion of emerging marine industries is rising. In the future, the focus of China's marine economic work should be to maintain the current development momentum of China's marine economy, relieving the short-term impact of the epidemic on supply and demand as soon as possible, make the future development back to the previous normal level, give full play to the advantages of national marine industry and industry and further improve the level of regional integration. Under this premise, it is expected that Gross Ocean Product of China will exceed 900 billion yuan in 2021, marine economic growth will reach 9\%, and the Gross Ocean Product of China will exceed 100,000 billion yuan in 2022. Each economic zone will return to normal levels of growth, and the economic zone on the west coast of the Straits will grow faster. For traditional industries, coastal tourism, marine mining, oil and gas industry will develop faster, while the marine chemical industry, marine biomedical industry and seawater utilization industry will grow faster than other emerging industries. It cannot be ignored that the global economy is still facing great uncertainty, which will exert unpredictable influences on the development of China's marine economy.

\section{Policy recommendations for China's marine economic development}

6.1 Making innovations in the development model of the marine economy and accelerating the transformation and upgrading of the marine industrial structure

To solve the increasingly prominent marine ecological environment problems in China, it is necessary to change the backward model of development, adapt to the current environment of scientific and technological innovation and sustainable development, optimize the industrial structure and form a green development model that conforms to the characteristics of China's marine economic development. Promote a shift from a single goal of rigid growth to a high-quality sustainable development paradigm, shifting the focus of marine economic development from labor-intensive to knowledge-intensive industries. Improve the scientific development and utilization of marine resources and change the extensive resource development route. Replacing exhaustible non-renewable marine energy with new sources of marine energy can change the path of development. China should try to coordinate its marine industrial layout, optimize industrial structure, cultivate green industry, solve the imbalance of marine industrial structure and the unreasonable layout thereof and continue to consolidate the industrial structure of " $3-2-1$ ". To promote the development of marine industry to the emerging marine industry tilt, increase government support, strengthen marine-related personnel training and promote the integration of industry, university, research and investment-system construction, China should develop mariculture breeding, expand the scale of deep-water cage culture, improve the scientific and technological content of the marine primary industry, promote the high-end traditional industry and realize the development of science and technology. Meanwhile, it is suggested to promote the marine industry cluster, avoid the marine industry's excesses of the past, encourage the region to rely on their own marine characteristics to build coastal industrial parks, form a complete industrial chain, promote primary, secondary and tertiary marine industries and realize the synergistic docking of land and sea industries.

\subsection{Innovation in the management system of the marine economy and improvement of the ability to regulate and manage the marine economy}

The marine economic management system is an important guarantee for the development of marine economy. Over times, the marine management system should also be reformed and innovated. Only a management system adapted to the current marine economic development 
can promote the sustainable development of marine economy. It is necessary to improve the legal system governing conduct in the marine economy and provide a good legal environment for the development thereof; at present, the legal context of the marine economy in China is constantly improving. However, there is a lack of unity between regional departments and a failure to form a perfect mechanism. It is necessary to strengthen marine legislation to adapt to the development of modern marine economy. Combined with the actual situation of the region, marine management standards should be established to combine the decentralization of marine management functions with centralized, hierarchical management. Strengthening the environmental protection of marine resources and developing the concept of green marine management should improve the relevant systems of marine resource development and management and sanctions punishing marine polluters, use the Internet and big-data to strengthen China's marine management and monitoring capabilities, strengthen law enforcement and explore the establishment of incentive mechanisms for marine pollution control and resource recovery. To establish and improve the coordination mechanism of marine economic management and solve the problem of incoordination in the process of marine economic development, China should improve the authority of marine administrative authorities, clearly divide the functions and powers of relevant marine departments, establish corresponding supervision and management institutions, construct scientific and reasonable decision-making system, realize information sharing and improve the regulation and management of the marine economy.

\subsection{Improvement of the statistical data pertaining to the marine economy and enhancement of the supporting role of marine big-data in decision-making}

Marine economic statistics is the basis of China's marine economic assessment and monitoring, academic research and international development comparison. It has important reference value in the construction of marine facilities, policy formulation and implementation. Government departments and relevant marine institutions should pay more attention to the construction of marine economic data statistical systems, pay attention to the construction of marine monitoring infrastructure, introduce high-tech equipment, improve the accuracy of the data obtained, promote the construction of a marine big-data platform, strengthen the integration of marine data and build a "smart marine data brain". We should strengthen the cooperation between government agencies and marine research departments, industry associations and other relevant marine institutions, jointly build a scientific marine economic operation evaluation system, expand the scope of marine data, refine marine data collection and collation and gradually establish a sound marine economic statistics system to form a "digital ocean" awareness. To improve the international recognition of China's marine data, the statistical caliber and variable names used in relation to the marine economy between countries are different. We should take the needs of national marine economic development as the starting point and take the accuracy, comprehensiveness and integrity of data as the guidance to improve the quality of marine economic statistics, form a perfect and efficient marine economic data statistics system and promote the construction of marine information. We should promote cooperation with the International Maritime Organization, conduct research projects on international comparability of marine economy, regularly publish global marine economic statistics products, improve the international influence of marine data and utilize effective and comparable data to improve the correctness of decision-making.

\subsection{Improve financial support and enhance the efficiency of marine scientific and transformational technological achievement}

The funds for the development of marine industry have been relatively single-source, and the amount of funds cannot meet the needs of marine economic development, and no complete
China's marine economy development 
MAEM

5,1

financing network has been formed, especially for marine science and technology. We should give full play to the leading role of the government, promote the diversified development of financing channels, provide support for qualified financial institutions and related marine enterprises to establish financial leasing companies and standardize the promotion of the government and social capital cooperation (PPP) model for the marine sector. Banks and other financial institutions should strengthen marine economic and financial services, establish special marine economic and financial services division, support qualified enterprises to list on the main board market, issue corporate bonds, increase credit support for emerging marine industries and establish public service platform for investment and financing of marine industry through information sharing. We should increase investment in marine science and technology through government support to establish a special policy guarantee company, for small and medium-sized enterprises in the field of marine science and technology and research institutions to provide specialized financing guarantee business and guide more funds into the field of marine science and technology. Through capital investment, the traditional marine industry is promoted to a high-end direction, and the transformation of scientific research achievements into actual productivity is promoted. The international visibility of enterprises is improved, and foreign investment is attracted to improve the efficiency of the transformation of marine scientific and technological achievements.

\subsection{Control of the novel coronavirus pandemic and acceleration of the safe and orderly development of marine economy}

The novel coronavirus pandemic is having serious effects on the world: stricter prevention, stricter control and a fight against the pandemic are necessary conditions for promoting economic development, the basis for doing a good job of "Six Stability" and implementing "Six Security" and the primary task of the current development of marine economy. We should actively establish anti-epidemic maritime "safety lines" and cut off the virus input chain. We should increase the number of anti-epidemic personnel according to the situation in different regions, implement classified control of all types of docks and ships, mark regional risk levels, minimize unnecessary contact between shippers and shore personnel, supervise overseas entry personnel to undertake pre-entry declaration, entry inspection and quarantine observation after entry, ensure the registration and inspection of personnel on-board and offboard and undertake effective disinfection. In addition to the prevention and control of personnel, we should also pay attention to the safety of marine imported products, especially aquatic products. It is necessary to supervise and record the source and treatment of imported products, strengthen the detection of related products and prevent products contaminated by new coronavirus from entering the market. In view of the new coronavirus pandemic, marinerelated departments should introduce certain preferential policies, appropriately improving the proportion of special fund subsidies for the marine economy and accelerate the comprehensive recovery of marine production. We must actively pay attention to the development of the marine economy, monthly summary scheduling, while solving existing problems. According to the experiences and learning arising from the pandemic, we should increase the coverage of fishery and other risk species, reduce the production and operational risk caused by such pandemics and promote the safe and orderly development of China's marine economy.

\section{References}

Li, H. and Gao, Q. (2017), "Scientific and technological progress, marine economic development and ecological environment change", Economic Management in East China, Vol. 31 No. 12, pp. 100-107. 
Li, X.H. and Zhang, Z.H. (2020), "Retrospect and prospect of 70 years' marine finance policy of new China", Journal of Zhejiang Ocean University, Vol. 37 No. 01, pp. 9-17.

Li, Y.H., Wang, W.T., Li, X.M., Jie, X.M., Han, P., Sun, Q., Wang, H. and Sun, H. (2019), "Research on China's marine science and technology development and cooperation with countries along the 'Belt and Road”, Journal of Marine Technology, Vol. 38 No. 03, pp. 100-106.

Lin, X.H. (2020), "The Global Ocean economy in 2030: influencing factors, trends, and suggestions", Journal of the Pacific, Vol. 28 No. 01, pp. 50-63.

Liu, K. (2020), "Innovative development path to promote high quality development of marine economy in China", Democracy and Science, No. 01, pp. 41-43.

Sun, C.Z., Guo, K.M. and Zou, W. (2017), "The coordination and response between regional marine economy and marine science and technology in China”, Resource Science, Vol. 39 No. 11, pp. 2017-2029.

Wang, H.J., Xia, F., Pan, Q. and Yang, L. (2020), "Finance supports the development of marine economy: the main practice of six provinces and cities including Guangdong and Shanghai and its enlightenment to Hainan”, Journal of Nanjing Municipal Party School, No. 01, pp. 66-71.

Zheng, L. and Peng, X. (2019), "Discussion and practice on the quality control method of marine economic statistics", Marine Economy, Vol. 9 No. 03, pp. 55-64.

Zheng, L., Fu, R.Q., Liu, S.B., Zhao, Z. and Peng, X. (2019), "Introduction research of statistical data quality assessment methods in the field of marine economy", Marine Economy, Vol. 9 No. 01, pp. $47-52$.

\section{Corresponding author}

Yin Kedong can be contacted at: yinkedong@ouc.edu.cn
China's marine economy development

For instructions on how to order reprints of this article, please visit our website:

www.emeraldgrouppublishing.com/licensing/reprints.htm

Or contact us for further details: permissions@emeraldinsight.com 